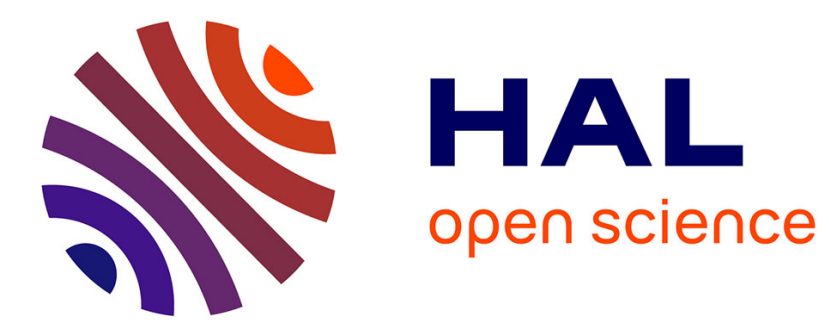

\title{
Thermal analysis and new insights to support decision making in retrofit and relaxation of heat exchanger networks
}

Antonio Piacentino

\section{- To cite this version:}

Antonio Piacentino. Thermal analysis and new insights to support decision making in retrofit and relaxation of heat exchanger networks. Applied Thermal Engineering, 2011, 31 (16), pp.3479. 10.1016/j.applthermaleng.2011.07.002 . hal-00789872

\section{HAL Id: hal-00789872 \\ https://hal.science/hal-00789872}

Submitted on 19 Feb 2013

HAL is a multi-disciplinary open access archive for the deposit and dissemination of scientific research documents, whether they are published or not. The documents may come from teaching and research institutions in France or abroad, or from public or private research centers.
L'archive ouverte pluridisciplinaire HAL, est destinée au dépôt et à la diffusion de documents scientifiques de niveau recherche, publiés ou non, émanant des établissements d'enseignement et de recherche français ou étrangers, des laboratoires publics ou privés. 


\section{Accepted Manuscript}

Title: Thermal analysis and new insights to support decision making in retrofit and relaxation of heat exchanger networks

Authors: Antonio Piacentino

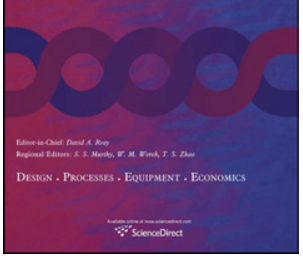

PII:

S1359-4311(11)00343-7

DOI:

10.1016/j.applthermaleng.2011.07.002

Reference: $\quad$ ATE 3628

To appear in: Applied Thermal Engineering

Received Date: 18 November 2010

Revised Date: 1 June 2011

Accepted Date: 2 July 2011

Please cite this article as: A. Piacentino. Thermal analysis and new insights to support decision making in retrofit and relaxation of heat exchanger networks, Applied Thermal Engineering (2011), doi: 10.1016/ j.applthermaleng.2011.07.002

This is a PDF file of an unedited manuscript that has been accepted for publication. As a service to our customers we are providing this early version of the manuscript. The manuscript will undergo copyediting, typesetting, and review of the resulting proof before it is published in its final form. Please note that during the production process errors may be discovered which could affect the content, and all legal disclaimers that apply to the journal pertain. 


\section{Highlights}

- A procedure for retrofit and relaxation of existing HENs is presented

- The existing HEN and a MER design are preliminarily diagnosed to assess targets

- Innovative diagrams and indicators are used to identify improvement directions

- Energy targets, heat transfer area and number of shells are simultaneously examined

- Relaxation paths should be pursued at a limited extent, to minimize total costs 


\title{
Thermal analysis and new insights to support decision making in retrofit and relaxation of heat exchanger networks
}

\author{
Antonio Piacentino \\ Department of Energy \\ University of Palermo \\ Viale delle Scienze, 90128, Palermo, Italy
}

\begin{abstract}
Pinch analysis offers a rational framework for identifying energy saving targets and designing efficient heat recovery networks, especially in process industry. Several scientists have contributed to improve and automate the original pinch method over the last decades, increasing its capability to deal with a number of specific issues; the expertise of the analyst,however, remains determinant in achievingoptimal results. In this paper a procedure for retrofit of existing networks is proposed, based on an integrate use of several techniques (either existing or innovative). The diagnosis of the existing network and of a "Minimum Energy Requirement" configuration emerges as a useful preliminary instrument for the retrofit study. Then, an innovative spider-type diagram is presented to identify a hierarchic order among a set of retrofit topologies and the most promising relaxation paths for each network topology. The procedure is aimed at offeringa conceptual-interpretative approach to energy analysts, to identify preferential routes in networks' retrofit (and exclude the least promising improvement directions of the existing network); it should be therefore conceived as alternative to algorithms for automatic optimization of heat exchanger networks. The focus is mainly put on the energetic performance of the different schemes (evaluated by thermal analysis of the involved heat exchangers), but the methodology finally enables the energy analyst to identify solutions achieving near-minimum total costs.
\end{abstract}

Keywords: thermal analysis, heat exchanger networks, exergy destruction, retrofit, relaxation

\section{Introduction}

Pinch analysis has been revealing a technique of primary interest for the design and improvement of Heat Exchanger Networks (HENs), due to its simple formalism and its efficient tools that enable even non expert analysts to recognize energy saving targets for specific processes.

A very interesting application of pinch techniques is related with retrofit of existing HENs: most of industrial processes, in fact, already implement some heat integration solutions, but these lead to sub-optimal results and further margins for energy saving usually exist. A first approach to the problem, proposed by Tjoe and Linnhoff [1], is known as the $\alpha$ method and is based on assuming same area efficiency $\alpha$ for the existing and the retrofitted HEN; the network design is obtained manually, according to a potentially time consuming procedure. Carlsson et al. [2] proposed a matrix method to account for the cost of exchangers' area, piping and pressure drops; the method does not include energy targeting. Another interesting approach, based on the network pinch concept, was presented by Asante and Zhu [3]; these authors preserved the valuable role of the analyst's expertise, through a highly interactive procedure oriented to gradually debottleneck the network, removing network pinches. A "merit order" between topology modifications is fixed during a "diagnosis stage"; the most convenient modified topology is then optimized by mathematical programming techniques.

Corresponding author. Tel.: +39091 23861952, Fax: +39091484425

E-mail address: piacentino@dream.unipa.it 


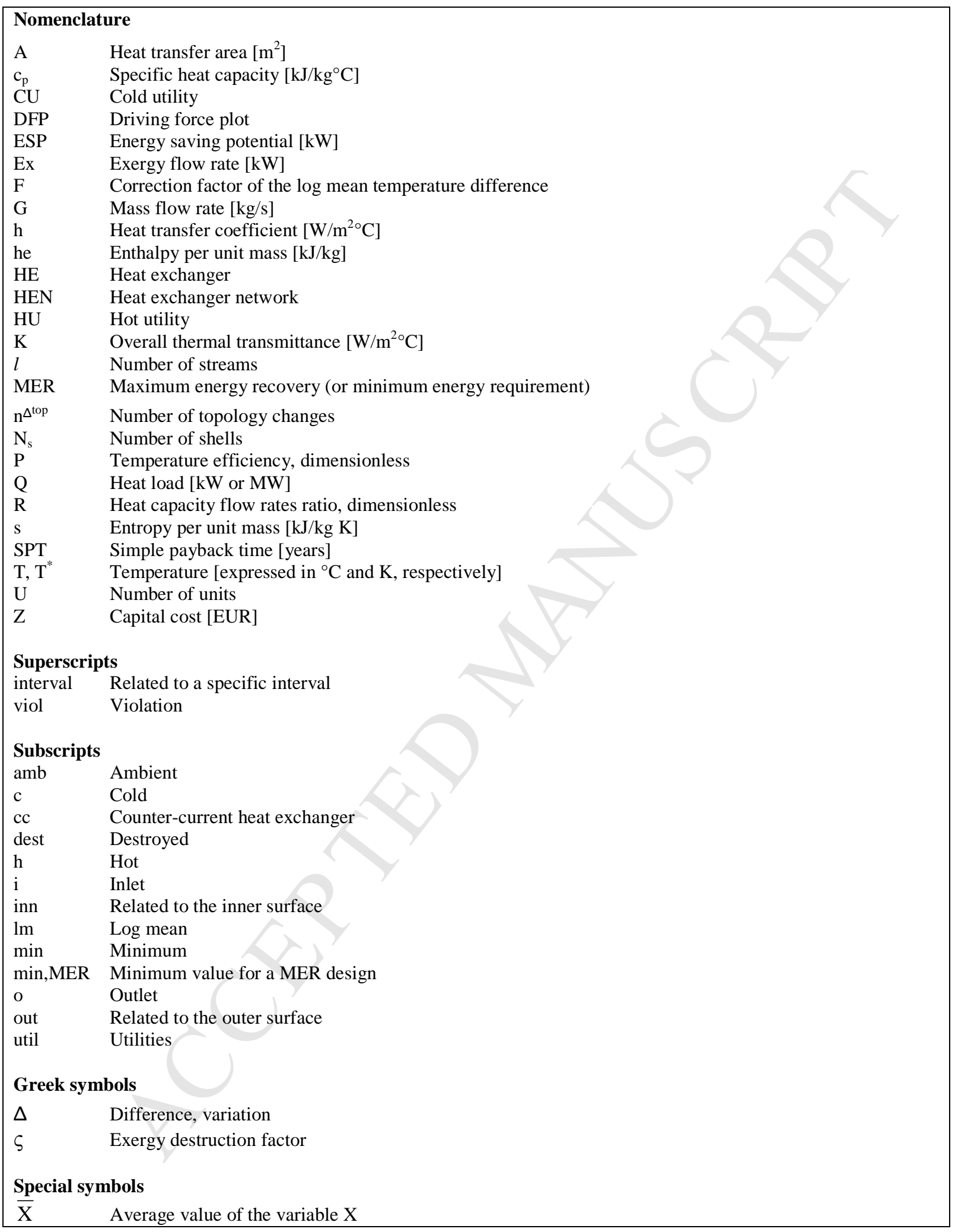

Although focused on HEN synthesis, and not on retrofit, the Remaining Problem Analysis method by Ahmad and Smith [4] should alsobe cited. This method, in fact, provides targets for the minimum number of shells according to a procedure based on thermal analysis of heat exchangers. Then, when diagnosing a Maximum Energy Recovery design 
or the existing HEN, it allows evaluating margins for a reduction in the number of shells; this potential use of the method for retrofit problems will be discussed below.

Another main research line is based on an extensive use of mathematical programming or evolutionary algorithms to solve the retrofit problem. Ciric and Floudas proposed a two-stage approach based on Mixed Integer Linear Programming (MILP) [5]; more recently, Rezaei and Shafiei have approached the same problem by a hybrid Non Linear Programming/Genetic Algorithm (NLP/GA) method [6].

Other recent works have proposed highly innovative approaches. Varbanov and Klemeš have addressed a couple of special casesunder the "network pinch framework", providing rules for paths construction oriented to debottleneck HENs [7]; in the same paper the authors define a "retrofit-specific heuristics" and a "heat-exchange process heuristics", both based on relevant (although partially intuitive) concepts on the rational use of the available driving force for heat transfer. Nordman and Berntsson have proposed an innovative use of "advanced composite curves" to assess costeffectiveness of HEN's retrofit solutions [8]. The possibility to use these advanced composite curves in low temperature applications has been recently proven by Ruohonen and Ahtila, with reference to a retrofit problem in a mechanical pulp and paper mill [9].A refinement of the method proposed by Asante and Zhu has been recently provided by Smith et al. [10]; the authors improved the network pinch method, increasing its capability to deal with variable (i.e. temperature-dependent) thermal properties of streams and with an innovative cost-based criterion for the identification of the most promising topologies. A different approach was proposed by Osman et al. [11]; the procedure attempts at generating retrofit options, created by shifting the heat load from HEN utilities through individual utility paths. This method adopts an "Exchanger Minimum Approach Temperature", instead of a $\Delta \mathrm{T}_{\min }$-based approach at network level; among its limits, the incapability to explore the whole solutions space due to the absence of topological modification. Finally, a few words should be spent for the research line known as "self-heat recuperation technology". This approach overcomessome limits of the Pinch Method, identifying further margins for energy saving; it has been applied with success in several process industries [12], allowing for recuperation of low-grade heat from effluent gaseous streams by recompression and reuse of these streams.

This brief literature survey allows us to recognize that most scientists have oriented their efforts toward more or less rigorous approaches, looking for optimal retrofit design; in real world applications, however, finding a "good solution" is essentially needed. In [3] several sources of uncertainty were discussed, which may affect the reliability of purely analytical solutions, thus testifying that an "optimal solution" is as appreciable as a "good and robust (i.e. scarcely sensitive to approximation in input data) solution".

Rather than presenting innovative approaches, this paper is aimed at:

- providing energy analysts with a better understanding of some intrinsic features of HENs' retrofit problems;

- enabling analysts to identify easily near-optimal retrofit and relaxation strategies, by a non-automatic procedure.

A heuristic/interpretative approach will be presented, based on the combined use of different techniques; some original tools will be also introduced.

Let us briefly list the techniques adopted and formulate the improvements expected over the state of the art:

- Two instruments will be adopted to provide an in-depth understanding of sub-optimal uses of the available driving force in the existing HEN, both close and far from the network pinch:

1. A graphic tool, the so-called "Driving Force Plot", usually adopted for the evaluation of Maximum Energy Recovery (or Minimum Energy Requirements, MER) design; 
2. An innovative approach, based on "exergy destruction factors", that provides a quantitative analysis of the potential energy saving associated with any heat exchanger.

Both these instruments (the former rarely used in literature, the latter innovative) will present the advantage to provide information at "overall network" level, differently than the conventional techniques based on the search for network pinches (which only suggest the current bottleneck for a network topology).

- It will be shown that a multi-approach diagnosis ofa Maximum Energy Recovery design may suggest to the energy analyst whether this configuration should be considered "technically interesting" (thus representing a target for a bottom-up retrofit process) or not. Of course, the relevance of economic aspects will be properly kept into account;

- In literature there is a lack of instruments for the simultaneous comparison of energetic performances and other cost-influencing aspects (such as the morphology of the network, in terms of heat transfer areas and number of shells needed for shell and tubes heat exchangers). This paper will introduce an innovative tool, represented by a spider-type graph described in Section 5.3, that enables the energy analyst to:

1. Identify a hierarchic order among several retrofit topologies, in terms of marginal energy savings achievable (compared to the existing HEN) and additional complexity of the network;

2. Recognize, a priori, if and at what extent a given HEN design would exploit major benefits from relaxation;

3. Identify, basing on analytical indicators, the most promising relaxation strategies for any HEN topology;

- At the end of the paper, the energetic and economic results of relaxed retrofit topologies will be mapped over a wide range of heat transfer areas. Such maps will be used to identify general trends, that energy analysts should be aware of before addressing retrofit problems.

When supported by optimization tools, the analyst will probably avoid performing such analyses, relying on the outputs provided by the software. This paper, on the contrary, is targeted for energy analysts looking for more conceptualinterpretative approaches; the final goal of the paper evidently consists of driving such analysts toward near-optimal solutions by a well-structured procedure.

\section{The case study: aromatics plant}

This paper is not oriented to introduce innovative optimization methods, but to present an innovative and harmonic use of several available techniques; in the meantime some innovative tools are presented, which could provide the analystwith a better understanding of any HEN retrofit problem. An unusual approach is then adopted; rather than introducing a demonstrative case study at the end of the paper,it is introduced here, at the very beginning of the paper. It will be thus possible to describe step by step the application of the different techniques to the examined case study, while discussing the relevance and possible use of the obtained results. At the end of the paper the proposed multiapproach procedure will be schematically resumed.

Also, due to the illustrative and methodological scope of the paper, referring to a well-known case study derived from literature seems convenient. In particular, an aromatics plant firstly presented in [13] will be examined; its simplified lay-out is schematically presented in Fig. 1, with the associated grid diagram of the existing heat recovery network drawn in Fig. 2. Inlet and target temperatures for each stream are presented in Table. 1; throughout the paper, temperatures will be mainly expressed in ${ }^{\circ} \mathrm{C}$ (adopting the symbol " $\mathrm{T}$ ", see Nomenclature), whereas the symbol " $\mathrm{T}$ ", will be used to express temperatures in Kelvin, only when needed. In this section just the most important features of the 
examined HEN are described, being the reader invited to examine, for further details, reference [14] where an accurate description of the plant is provided.

Let us briefly clarify the reason for considering two distinct streams, no. 5 and no. 6 (which could apparently represent a unique stream). Actually, through the Heat Exchanger X (indicated only in Fig. 1) the stream is cooled from $307^{\circ} \mathrm{C}$ to $220^{\circ} \mathrm{C}$, and it releases heat to the reboilers of the distillation columns. In the present study, this section of the plant is assumed as "not modifiable" (following the approach proposed in [14]) and is consequently excluded from the pinchbased retrofit analysis. Then, the need to consider two different streams no. 5 and no. 6 is evident.

The available data are disaggregated at sub-stream level. The feed (stream 1), for instance, achieves the reaction temperature in two steps (Heat Exchanger A and vaporizer); it undergoes a heating process that can be associated with two average heat capacity flow rates, $\mathrm{G} \overline{\mathrm{c}_{\mathrm{p}}}$, over the steps "1a" (Heat Exchanger A) and "1b" (vaporizer). Values of target temperatures, $\mathrm{G} \overline{\mathrm{c}_{\mathrm{p}}}$ and heat flows for each sub-stream are presented in Table 1; in this table the values are presented in bold font when they represent the target temperature for the stream.

This aromatics plant represents a best case study for our analysis, due to the difficulties in retrofitting such systems characterized by a large "near-pinch region" [14], i.e. a large region where the composite curves maintain at a $\Delta \mathrm{T}$ close to $\Delta \mathrm{T}_{\min }$.

\section{Multi-targeting diagnosis of a MER configuration}

A Maximum Energy Recovery design can be easily obtained by applying the well-known rules of the Pinch Design Method, firstly presented by Linnhoff and Hindmarsh [15]. Starting at the pinch, i.e. the most constrained point, we move toward the "far from pinch" regions, always fulfilling the so-called "golden rules", i.e. avoiding to use cold utilities above pinch or hot utilities below pinch and to transfer heat across pinch [14]. In order to minimize the number of units, the so-called "tick-off heuristics" is applied, that is the maximization of the rated heat transfer on each match under the $\Delta \mathrm{T}_{\min }$ and the golden-rules constraints. In our case the application of Pinch Design Method suggested that pinch is located at $145^{\circ} \mathrm{C}$ (i.e. at $150{ }^{\circ} \mathrm{C}$ on the hot streams side and at $140{ }^{\circ} \mathrm{C}$ on the cold stream side, having been assumed a $\Delta \mathrm{T}_{\min }=10^{\circ} \mathrm{C}$ ); this result can be immediately obtained by any simple worksheet like [16]. The obtained MER design is presented in Fig. 3.a,b, respectively for the above and below pinch region; small $\Delta \mathrm{T}_{\min }$ violations have been allowed to simplify the network.

Let us clarify the symbolism adopted in Fig. 3 (a key is also provided in the figure): close to each heat exchanger, its heat rate (expressed in MW, within a continuous line), its product "KA" (calculated for a counter-current configuration, expressed in $\mathrm{kW} /{ }^{\circ} \mathrm{C}$ and underlined in the figure), its log-mean temperature difference (expressed in ${ }^{\circ} \mathrm{C}$ and represented within a discontinuous line) and its eventual $\Delta \mathrm{T}_{\min }$ violation (expressed in ${ }^{\circ} \mathrm{C}$ and represented within a small circle) are provided.

Actually, $\Delta \mathrm{T}_{\min }$ violations usually result from relaxation of a "MER design with null $\Delta \mathrm{T}_{\text {min }}$ violations"; hence, from a rigorous perspective, the MER design presented in Fig. 3.a,b would not represent an actual "starting point" for the relaxation process. Also, let us remember that where a $\Delta \mathrm{T}_{\min }$ violation occurs, we locally have a very low "driving force" for heat transfer, resulting in the need for an increased heat transfer area. In this specific case, however, the presented design is assumed as an acceptable MER design, because of the following reasons: 
- These minor $\Delta \mathrm{T}_{\min }$ violations do not result from relaxation of a "MER design with null $\Delta \mathrm{T}_{\min }$ violations"; they were introduced during the definition of a MER lay-out, when attempting to apply the golden rules. In fact, because of the tighten thermal constraints in our case study, extensive "cycling matching" or "stream splitting" (concepts well known to specialists in pinch analysis) [14] should have been applied if no $\Delta \mathrm{T}_{\min }$ violations were allowed for, thus resulting in a higher number of small heat exchangers. Assuming a reference MER design with a higher number of small heat exchangers, in comparison with the design shown in Fig. 3, would slightly complicate for the reader the interpretation of the analyses proposed below in the paper.

- The $\Delta \mathrm{T}_{\min }$ violations provoked negligible variations in the capacity and heat transfer area of most heat exchangers, with respect to the values that would have resulted from a "MER design with null $\Delta \mathrm{T}_{\min }$ violations". The highest $\Delta \mathrm{T}_{\min }$ violation, in fact, occurs on a 6-8 match (see Fig. 3.a) characterized by a high log-mean temperature difference $\Delta \mathrm{T}_{\mathrm{lm}}$.

Then, let us assume the design presented in Fig. 3.a,b as a reference MER design.

In the following sub-sections the proposed MER design will be diagnosed to recognize whether, and at what extent, it could represent a realistic target for a "bottom-up" improvement of the existing HEN.

\subsection{Targeting for the number of units}

A main risk is to have designed a MER configuration with a number of units much higher than the minimum feasible, because the examined plant has a large near pinch region which often did not allow an extensive application of the "tick-off heuristics".Actually, we get:

$$
\begin{gathered}
\mathrm{U}_{\text {network }}=\mathrm{U}_{\text {he }}+\mathrm{U}_{\text {util }}=19 \\
\mathrm{U}_{\text {min,MER }}=(l-1)_{\text {above pinch }}+(l-1)_{\text {below pinch }}=17
\end{gathered}
$$

where U indicates the number of units, $l$ the number of streams and the subscripts "network" and "min,MER" respectively refer to the design presented in Fig. 3 and to the minimum theoretical number of units for a MER design. In Eq. 2 the minimum number of units for the MER design is calculated by summing up the minimum number of units needed above pinch (equal to the number of streams above pinch, minus one) and below pinch.

A " $U_{\text {network }}-U_{\text {min,MER }}=2$ " redundancy emerges, related to the presence of two loops indicated in bold hatched line in Fig. 3.a,b.

\subsection{Targeting for the number of shells}

Temperature cross, that is the difference (when positive) between the outlet temperature of cold stream and the outlet temperature of hot stream, limits the heat transfer efficiency and increases the heat transfer area needed for a given heat exchanger capacity. The problem is caused by the presence of some regions, within the heat exchanger volume, that result "non active" for heat transfer due to the local inversion of the driving force; in such cases, fractioning the overall heat exchange area into a number of distinct shells represents a possible solution. A HEN design based on detailed thermal analyses should account for this aspect.

The minimum number of shells $\mathrm{N}_{\mathrm{s}}^{\mathrm{min}}$ can be calculated by the analytical method developed by Ahmad et al. [17], which consists of three phases:

1. The composite curves are divided into enthalpy intervals, as shown in Fig. 4, and, for each interval, the terminal temperatures are used; 
2. The $\mathrm{N}_{\mathrm{s}}$ for each interval is determined by assuming that the $\Delta \mathrm{T}_{\mathrm{lm}}$ correction factor, $\mathrm{F}$, maintains higher than 0.8 ; this condition indicates that heat transfer maintains efficient all over the heat exchanger volume, thus excluding dramatic increases in the heat transfer area needed. Let us follow an approach proposedin [18] and explained in detail in [19]. After having defined two dimensionless parameters usually adopted in the thermal evaluation of heat exchangers, i.e. the "temperature efficiency" $\mathrm{P}$ and the "heat capacity flow rates ratio" R:

$$
\begin{gathered}
P=\frac{T_{c, o}-T_{c, i}}{T_{h, i}-T_{c, i}} \\
R=\frac{T_{h, i}-T_{h, o}}{T_{c, o}-T_{c, i}}=\frac{\left(\overline{c_{p}}\right)_{c}}{\left(G \overline{c_{p}}\right)_{h}}
\end{gathered}
$$

let us introduce another factor, defined by:

$$
\mathrm{X}_{\mathrm{P}}=0.5 \mathrm{P}\left(\mathrm{R}+1+\sqrt{\mathrm{R}^{2}+1}\right)
$$

The parameter $\mathrm{X}_{\mathrm{P}}$, expressed by Eq. 5 and introduced in [18], indicates a relative measure of $\mathrm{P}$ with respect to the value $\mathrm{P}_{\max }$ corresponding to the vertical asymptote of a typical $\mathrm{F}(\mathrm{R}, \mathrm{P})$ profile; for sufficiently high values of $\mathrm{X}_{\mathrm{P}}=\mathrm{P} / \mathrm{P}_{\max }$, the point on the $\mathrm{F}(\mathrm{R}, \mathrm{P})$ diagram is located before the "descendant knee" of the $\mathrm{F}(\mathrm{R}, \mathrm{P})$ curve and relatively high values of $\mathrm{F}$ are obtained [18].

Assuming to install only "TEMA E-type"heat exchangers with shells connected in series and with the hot fluid in the shell side, a minimum 0.85 value for $\mathrm{X}_{\mathrm{P}}$ should be imposedto obtain values of the $\Delta \mathrm{T}_{\mathrm{lm}}$ correction factor, F, higher than 0.8 [18].

In order to calculate the number of shells for each interval, in [17] the following expressions were proposed:

$$
\begin{gathered}
\mathrm{W}=\frac{\mathrm{R}+1+\sqrt{\mathrm{R}^{2}+1}-2 \mathrm{R} \mathrm{X}_{\mathrm{P}}}{\mathrm{R}+1+\sqrt{\mathrm{R}^{2}+1}-2 \mathrm{X}_{\mathrm{P}}} \\
\mathrm{N}_{\mathrm{s}}^{\text {interval }}=\frac{\ln \left(\frac{1-\mathrm{RP}}{1-\mathrm{P}}\right)}{\ln \mathrm{W}}
\end{gathered}
$$

The number of shells required for each stream, including the utilities, is then obtained by summing up the number of shells for each interval where the stream occurs [17]. Once calculated $\mathrm{N}_{\mathrm{s}}$ for each interval and stream, the minimum feasible number of shells for a MER design is calculated by [18]:

$$
\mathrm{N}_{\mathrm{s}}^{\min }=\sum_{\mathrm{j} \in\{\text { streams }\}}\left(\mathrm{N}_{\mathrm{s}}\right)_{\text {stream } \mathrm{j}}-\sum_{\mathrm{i} \in\{\text { intervals }\}}\left(\mathrm{N}_{\mathrm{s}}^{\mathrm{i}}\right)
$$

In this case $\mathrm{N}_{\mathrm{s}}^{\min }=59$ was obtained; a detailed simulation of the MER design presented in Fig. 3, based on Eq. 3-7 and performed by a self-coded Excel sheet (which implements Ahmad's method), allows us to calculate $\mathrm{N}_{\mathrm{s}}^{\mathrm{MER}}=60$. Then, a one shell redundancy emerges.

\subsection{Targeting for the heat exchange area}

A similar comparison can be made between the heat transfer area to be installed in the MER design (see Fig. 3) and the "area target", i.e. the minimum area theoretically needed to ensure the desired heat transfer between hot and cold streams, according to the "composite curves overlap" associated with the $\Delta \mathrm{T}_{\min }$ imposed. The area target is calculated by summing up the minimum areas required for allthe intervals identified in Fig. 4 on the composite curves. 
The conventional approach for calculating the minimum area required for a generic interval " $\mathrm{i}$ " is based on the so-called "Bath" formula [19,20]:

$$
A_{\text {intervali }}=\frac{1}{F_{i}\left(\Delta T_{l m}\right)_{i}}\left(\sum_{j \in\{\text { hot streams, } i\}} \frac{Q_{j, i}}{h_{j, i}}+\sum_{k \in\{\text { cold streams,i }} \frac{Q_{k, i}}{h_{k, i}}\right)
$$

Equation 9 neglects tube wall resistances and assumes the area ratio $\mathrm{A}_{\text {out }} / \mathrm{A}_{\text {inn }}$ equal to 1 . This expression is well known among specialists in synthesis or retrofit of heat exchanger networks; it evidently results from the sum, extended to all the streams of a generic interval "i" (see Fig. 4), of the areas needed for heat transfer between two genericstreams in the same interval. Being for a generic heat exchanger:

$$
\mathrm{Q}=\mathrm{F} \cdot(\mathrm{K})_{\text {inn }} \cdot \mathrm{A}_{\text {inn }} \cdot \Delta \mathrm{T}_{\mathrm{lm}}=\mathrm{F} \cdot(\mathrm{K})_{\text {out }} \cdot \mathrm{A}_{\text {out }} \cdot \Delta \mathrm{T}_{\mathrm{lm}}
$$

we get:

$$
\frac{1}{(\mathrm{~K})_{\text {inn }} \cdot \mathrm{A}_{\text {inn }}}=\frac{1}{(\mathrm{~K})_{\text {out }} \cdot \mathrm{A}_{\text {out }}}=\frac{1}{\mathrm{~h}_{\text {inn }} \mathrm{A}_{\text {inn }}}+\frac{1}{\mathrm{~h}_{\text {out }} \mathrm{A}_{\text {out }}}
$$

Equation 11 already neglects fouling and wall resistances; assuming $\mathrm{A}_{\text {out }} / \mathrm{A}_{\text {inn }}$ equal to 1 we obtain $\mathrm{K}_{\mathrm{inn}}=\mathrm{K}_{\text {out }}$ and also:

$$
\mathrm{A}_{\mathrm{inn}}=\mathrm{A}_{\text {out }}=\frac{\mathrm{Q}}{\mathrm{F} \cdot \Delta \mathrm{T}_{\mathrm{lm}}} \cdot\left(\frac{1}{\mathrm{~h}_{\mathrm{inn}}}+\frac{1}{\mathrm{~h}_{\text {out }}}\right)
$$

Equation 9 is obtained, as said, summing up for a generic interval the areas associated to the different matches, each one being calculated by Eq. 12. Equation 9 allows to account for a different heat transfer coefficient on each stream; in spite of its limits, discussed in detail in [14] and related with the assumption of "vertical" heat transfer between streams, this expression is usually assumed as approximately valid.

When gas-liquid finned tube exchangers are concerned, however, like in the examined aromatics plant that includes both liquid and gaseous streams, Eq. 9 cannot be used because the assumption $\mathrm{A}_{\text {out }} / \mathrm{A}_{\text {inn }} \cong 1$ is inconsistent. Let us derive a modified expression, dual to Eq. 9 and valid also for finned gas-liquid heat exchangers. For a gaseous stream matched with either a liquid or a 2-phase stream, a finned surface on the gas side is usually adopted, so that the following expression:

$$
\mathrm{h}_{\text {gas }} \mathrm{A}_{\text {gas-side }} \cong \mathrm{h}_{\text {(liquid)/(2-phase) }} \mathrm{A}_{\text {(liquid)/(2-phase)-side }}
$$

is valid, at least in terms of order of magnitude. Equation 13, in fact, indicates a condition where the penalty due to the low heat transfer coefficient on the gas-side has been properly mitigated by the additional fins area. Under the restriction imposed by Eq. 13, the expression in Eq. 11 becomes:

$$
\begin{aligned}
& \frac{1}{(\mathrm{~K})_{\text {gas-side }} \cdot \mathrm{A}_{\text {gas-side }}}=\frac{1}{(\mathrm{~K})_{\text {(liquid)/(2-phase) }} \cdot \mathrm{A}_{\text {(liquid)/(2-phase)-side }}}=\frac{1}{\mathrm{~h}_{\text {(liquid)/(2-phase) }} \mathrm{A}_{\text {(liquid)/(2-phase)-side }}}+\frac{1}{\mathrm{~h}_{\text {gas }} \mathrm{A}_{\text {gas-side }}} \cong \\
& \cong \frac{2}{\mathrm{~h}_{\text {(liquid)/(2-phase) }} \mathrm{A}_{\text {(liquid)/(2-phase)-side }}}
\end{aligned}
$$

Consequently, we obtain:

$$
\mathrm{A}_{\text {(liquid)/(2-phase)-side }}=\frac{\mathrm{Q}}{\mathrm{F} \cdot \Delta \mathrm{T}_{\mathrm{lm}}} \cdot \frac{2}{\mathrm{~h}_{\text {(liquid)/(2-phase })}}
$$

Comparing Eq. 12 and Eq. 15 we may conclude that: as long as gas/liquid or gas/two-phase exchangers are concerned, when fins area on the gas side allows to fulfill Eq. 13, the area on the unfinned side can be calculated by adopting an 
equation similar to Eq. 12, just replacing the heat transfer coefficient on the gas-side with the coefficient on the liquid/2phase side of the heat exchanger.

Summing up again the contributes of all the heat exchanges within a generic interval "i", the following "modified Bath formula" is obtained:

$$
A_{\text {intervali }}=\frac{1}{F_{i}\left(\Delta \mathrm{T}_{l m}\right)_{i}}\left(\sum_{j \in\{\text { liquid or }}\left(\sum_{\text {-phase streams, } i\}} \frac{\mathrm{Q}_{\mathrm{j}, \mathrm{i}}}{\mathrm{h}_{\mathrm{j}, \mathrm{i}}}+\sum_{\mathrm{k} \in\{\text { gaseous streams, } \mathrm{i}\}} \frac{\mathrm{Q}_{\mathrm{k}, \mathrm{i}}}{\mathrm{h}_{\mathrm{k} \text {-exchanger,i }}}\right)\right.
$$

The term $\mathrm{h}_{\mathrm{k} \text {-exchanger }}$ in Eq. 16 evidently indicates the heat transfer coefficient of the liquid or 2-phase stream eventually matched with the k-th gaseous stream, and this coefficient is fictitiously used on the gaseous stream-side due to the presence of additional fins area, as clarified above. The area $\mathrm{A}_{\text {interval } i}$ calculated by Eq. 16 will represent the total area on the unfinned side.Under the restriction given by Eq. 13, the expression provided in Eq. 16 will represent a dual formulation of the "Bath formula" adequate also for gas-liquid heat exchangers.

Of course, the use of Eq. 16 is a bit more complex than that of Eq. 9; at first sight, in fact,Eq. 16 could appear inappropriate for a pinch study where, for a generic interval $\mathrm{i}$, the actual matches are not known a priori. In case of simple lay-outs, however, it could occur that in a certain interval the liquid streams eventually matched with a gaseous stream have heat transfer coefficients of a same order of magnitude; in such cases the proposed approach could be easily implemented, as made in the following of this paper.

In Eq. 9 and 16 the correction factor F is included. The most common approaches for evaluating $\mathrm{F}$ are based on charts, which refer to a specific heat exchanger and to the dimensionless parameters P and R defined by Eq. 3 and 4 . Both pinch techniques and HEN retrofit problems, however, need increasingly automatic approaches; then, it is convenient to evaluate F analytically, basing on approaches available in literature. Below in this paper one of the simplest approaches is adopted, i.e. the so-called "Bowman-Mueller-Nagle F relationship" [21]; although developed more than seventy years ago, this analytical formulation is still widely used[22] and eventually refined for specific purposes [23,24].

For a one-pass shellside and two-pass tubeside exchanger, the following expression can be adopted for the correction factorF [21]:

$$
\mathrm{F}=\frac{\sqrt{\mathrm{R}^{2}+1} \ln \left(\frac{1-\mathrm{S}}{1-\mathrm{RS}}\right)}{(\mathrm{R}-1) \ln \left[\frac{2-\mathrm{S}\left(\mathrm{R}+1-\sqrt{\mathrm{R}^{2}+1}\right)}{2-\mathrm{S}\left(\mathrm{R}+1+\sqrt{\mathrm{R}^{2}+1}\right)}\right]}
$$

where:

$$
\begin{gathered}
S=\frac{\alpha-1}{\alpha-R} \\
\alpha=\left(\frac{1-R P}{1-P}\right)^{\frac{1}{N_{s}}}
\end{gathered}
$$

The analytical approach, implemented into an Exceel worksheet, allowed to perform a detailed thermal analysis and to calculate a target area for the MER design $\mathrm{A}_{\mathrm{MER}}^{\min }=23.35 \cdot 10^{3} \mathrm{~m}^{2}$. As the problem includes very tighten thermodynamic constraints, due to the large near pinch region, we can expect the MER design to have a just slightly 
higher heat transfer area than the target; this prediction is confirmed by the thermal analysis of the MER design, that provides an $\mathrm{A}_{\mathrm{MER}}=24.32 \cdot 10^{3} \mathrm{~m}^{2}$, just $4.1 \%$ higher than $\mathrm{A}_{\mathrm{MER}}^{\min }$.

The results achieved in the last three sub-sections testify that the MER design obtained is quite close to the targets from any viewpoint, thus representing an interesting target for the retrofit problem; its structure, however, is very different from the existing HEN. It remains to be assessed whether the MER design may represent an economically viable option for plant retrofit; the high degree of "area fractioning"resulted in the MER configuration (testified by the presence of several small heat exchangers above the pinch) suggests us that the bottom-up retrofit process will be probably interrupted before achieving the targets. Let us clarify this concept. A bottom-up retrofit process assumes as a starting point the existing HEN and moves toward the MER design by incremental improvements. Each improvement usually requires an additional capital investment for HEN modification and produces some marginal energy saving; it reveals convenient only when the marginal savings justify the higher capital investment, guaranteeing short payback periods or high internal rates of return for the investment. When the HEN has been substantially improved, any further increase in the efficiency can require too high marginal investments; in such cases, no further incremental improvements should be imposed and the retrofit process should be interrupted.

\section{Diagnosis of the existing HEN}

Most analytical approaches to HENs' retrofit are oriented to derive numerical indicators or identify network pinches, so as to recognize improvement directions. In this case, referring to the existing HEN and to its grid diagram in Fig. 2, the network pinch located on the hot side of HE B could be easily removed by a number of modifications, like using some high-grade heat released by stream 6 (or 9) to lead stream 3 to its target; the network pinch, however, would probably move towards the heat exchangers F, G or L, where further improvements would be less intuitive due to tighten thermal constraints. Let us adopt a more comprehensive approach to topology improvement, starting from a preliminary analysis of the inefficient heat exchanges in the existing HEN.

\subsection{Sub-optimal use of the available heat transfer driving force}

The main problem evidently consists in the sub-optimal use of heat transfer driving force at medium-high temperature; in this section some reflections on this aspect are proposed.Let us discuss the instruments that may support the analyst in recognizing the most inefficient uses of the available driving force, starting from the so-called Driving Force Plot (DFP). It is a plot of the temperature difference between the hot and the cold composite curves, versus the temperature of either cold or hot streams; in [18] its use is recommended for the analysis of MER configurations, in order to perform an easy comparison with the driving force of each individual heat exchanger. Let us consider an alternative use of this plot, oriented to diagnose the existing HEN; in Fig. 5 the DFP is presented, with the driving force profiles for any heat exchanger(the same identification of heat exchangers presented in Fig. 2 is here adopted).

In Fig. 5 any hatched line ( $\Delta \mathrm{T}$ for individual exchangers in the existing HEN) above the bold continuous line (available driving force, calculated from the composite curves) indicates an over-utilization of the available driving force.

Evidently most heat exchangers reveal a very inefficient use of the available driving force. Also, a hierarchy can be intuitively identified among them, as concerns the impact of the "thermal inefficiency" on the overall energy consumption. The heat exchangers overlapping the "highly constrained region" (between the two vertical lines in Fig. 5) are more critical than those outside this region; then, the hot side of HE L and the hot side of HE E, both close to this region, should be paidas much attention as the HE D, in spite of their lower gap from the bold line. This is because of 
the significance of the pinch; the over-utilization of driving force in the near pinch region, in fact, propagates its effects toward the higher-temperature "far from pinch" regions, and not the contrary.

\subsection{Modified exergy analysis: the exergy destruction factor}

An alternative approach to identify sub-optimal uses of the available driving force is here presented, based on a "modified exergy analysis". Once schematized the HEN as a black box, it is evident that, at fixed inlet and outlet conditions of the streams (coincident with their targets), any increase/decrease in the consumption of utilities is associated with an equal increase/decrease in the exergy destruction at HEN level; this concept will be cleared below (see the comments to Eq. 24). Let us neglect the exergy destruction due to friction losses (pressure drops in the exchanging streams) and focus the attention on the exergy destruction due to irreversible heat transfer; for countercurrent heat exchangers the three situations schematized in Fig. 6.a-c can be observed.

Indicating by the subscripts $\mathrm{h}$ and $\mathrm{c}$ respectively the hot and the cold stream, and by $\mathrm{T}^{*}$ the absolute temperature in Kelvin (obviously, $\mathrm{T}^{*}=\mathrm{T}+273.15$ ), exergy destruction in a generic heat exchanger is expressed by:

$$
E x_{\text {dest }}=\sum_{i \in\{\text { inlets }\}} E x_{i}-\sum_{o \in\{\text { outlets }\}} E x_{o}=\left(E x_{1}-E x_{2}\right)-\left(E x_{4}-E x_{3}\right)
$$

As an example, for a hot stream with a finite and constant $\mathrm{G} \overline{\mathrm{c}_{\mathrm{p}}}$ (i.e. with a non-null temperature variation, see Fig. 6.a) we have:

$$
\mathrm{Ex}_{1}-\mathrm{Ex}_{2}=\mathrm{G} \cdot\left[\mathrm{he}_{1}-\mathrm{he}_{2}-\mathrm{T}_{\mathrm{amb}}^{*}\left(\mathrm{~s}_{1}-\mathrm{s}_{2}\right)\right]=\mathrm{G} \overline{\mathrm{c}_{\mathrm{p}}} \cdot\left(\mathrm{T}_{1}^{*}-\mathrm{T}_{2}^{*}-\mathrm{T}_{\mathrm{amb}} \int_{2}^{1} \frac{\mathrm{dT}^{*}}{\mathrm{~T}^{*}}\right)=\mathrm{G} \overline{\mathrm{c}_{\mathrm{p}}}\left(\mathrm{T}_{1}^{*}-\mathrm{T}_{2}^{*}-\mathrm{T}_{\mathrm{amb}}^{*} \ln \frac{\mathrm{T}_{2}^{*}}{\mathrm{~T}_{1}^{*}}\right)
$$

while for a hot stream with an infinite $\bar{G} \overline{c_{p}}$ (see Fig. 6.b) we get:

$$
\mathrm{Ex}_{1}-\mathrm{Ex}_{2}=\left(\mathrm{he}_{1}-\mathrm{he}_{2}\right) \cdot\left(1-\frac{\mathrm{T}_{\mathrm{amb}}^{*}}{\mathrm{~T}_{1}^{*}}\right)
$$

An useful indicator for assessing the thermodynamic inefficiency of a heat exchanger is the "exergy destruction factor": $\varsigma=\frac{E x_{\text {dest }}}{Q}$

Of course, in pinch analysis a "specific indicator" like the exergy destruction factor $\zeta$ should be always coupled with the heat loads, in order to evaluate the contribute of any heat exchanger to the overall exergy destruction (and energy saving potential). Let us express theexergy destruction in a heat exchanger by ৎQ (see Eq. 23). Looking at the HEN as a black box and supposing the hot utility to be represented by a natural gas fuelled boiler, we may affirm that the energy (and exergy, being natural gas almost pure exergy) saving potential equals the total exergy destruction in the network:

$$
\mathrm{ESP}=\sum_{\mathrm{j} \in\{\text { heat exchangers }\}} \mathrm{Ex}_{\text {dest } \mathrm{j}}=\sum_{\mathrm{j} \in\{\text { heat exchangers }\}} \varsigma_{j} \mathrm{Q}_{\mathrm{j}}
$$

In fact, as there are no variations in exergy content of the streams entering or exiting the HEN (all streams, both in case of efficient or inefficient HENs, maintain their inlet and outlet conditions fixed), any marginal energy (and exergy) supply must be related with an additional exergy destruction by irreversible heat transfer.

The following expressions are obtained for $\varsigma$ (the subscript refers to the sub-figures "a", "b" and "c" in Fig. 6):

$$
\varsigma_{\mathrm{a}}=\frac{\mathrm{T}_{\mathrm{amb}}^{*}}{\mathrm{~T}_{1}^{*}-\mathrm{T}_{2}^{*}} \cdot \ln \frac{\mathrm{T}_{1}^{*} \cdot\left(\mathrm{T}_{3}^{*}\right)^{\mathrm{R}}}{\mathrm{T}_{2}^{*} \cdot\left(\mathrm{T}_{4}^{*}\right)^{\mathrm{R}}}
$$




$$
\begin{aligned}
& \varsigma_{\mathrm{b}}=\mathrm{T}_{\mathrm{amb}}^{*} \cdot\left(\frac{1}{\mathrm{~T}_{4}^{*}-\mathrm{T}_{3}^{*}} \cdot \ln \frac{\mathrm{T}_{4}^{*}}{\mathrm{~T}_{3}^{*}}-\frac{1}{\mathrm{~T}_{1}^{*}}\right) \\
& \varsigma_{\mathrm{c}}=\mathrm{T}_{\mathrm{amb}}^{*} \cdot\left(\frac{1}{\mathrm{~T}_{1}^{*}}-\frac{1}{\mathrm{~T}_{1}^{*}-\mathrm{T}_{2}^{*}} \cdot \ln \frac{\mathrm{T}_{1}^{*}}{\mathrm{~T}_{2}^{*}}\right)
\end{aligned}
$$

In Eq. 25the "heat capacity flow rates ratio" R represents the parameter defined by Eq. 4. The conceptual interest of Eq. 25-27 is different from that of the driving force plot; although both instruments reflect the thermodynamic inefficiency due to the use of an excessive driving force in some heat exchangers, the interpretation of the DFP could appear more intuitive. In fact, because of the nature of $\varsigma$ (it is a dimensionless parameter, expressing exergy destruction per unit heat load), suggestions on the best improvement directions of the existing HEN can be hardly derived by a simple list of numerical $\varsigma$ values, as those provided in Eq. 28.a-f (with reference to the notation adopted for the heat exchangers in Fig. 2):

$\varsigma_{\mathrm{A}}=0.109 ; \quad \varsigma_{\mathrm{B}}=0.070 ; \quad \varsigma_{\mathrm{D}}=0.106 ; \quad \varsigma_{\mathrm{E}}=0.046 ; \quad \varsigma_{\mathrm{F}}=0.094 ; \quad \varsigma_{\mathrm{G}}=0.057 ; \quad \varsigma_{\mathrm{L}}=0.109 \quad(28 . \mathrm{a}-\mathrm{f})$

The exergy destruction factors, however, could reveal very useful; the main advances offered by the proposed indicator with respect to a conventional "exergy loss analysis" are:

- $\quad$ Methodological: $\varsigma$ represents a measure of the intrinsic inefficiency of a heat exchanger, due to the inlet and outlet temperature of streams. The analyst is interested in knowing not only the exergy destruction rate at any heat exchanger, but also the difficulties to improve its exergetic performance. In other words, ranking the heat exchangers (in decreasing order) basing on the exergy destruction rate (in $\mathrm{kW}$ ) and ordinate the improvement process basing on this rank (i.e. from the first to the least exchanger in the obtained list) is not reasonable; a "scale factor", in fact, should be accounted for.Considering two generic heat exchangers A and $\mathrm{B}$, once observed that" $\mathrm{Ex}_{\text {dest }}^{\mathrm{A}}>\mathrm{Ex}_{\text {dest }}^{\mathrm{B}}$ " and " $\mathrm{Q}^{\mathrm{A}}>>\mathrm{Q}^{\mathrm{B}}$ ", we should not always conclude to prioritize the improvement of heat exchanger A; in fact, resulting $\varsigma^{\mathrm{B}}<\varsigma^{\mathrm{A}}$, we could rather affirm that "the highest scope for energy saving is associated with the HE A, but the "inefficient" temperature profiles of the HE B will probably offer larger margins for thermal improvement (by imposing, for instance, a minor modification in the inlet or outlet temperature of a stream)";

- Scientific: basing on the elements provided in this section, open margins for future research exist as concerns the potential use of exergydestruction factors. Focusing on Eq. 25, for instance, we note that $\varsigma$ increases with $\mathrm{T}_{1}^{*}\left(\mathrm{~T}_{3}^{*}\right)^{\mathrm{R}}$ high inlet temperature of the involved fluids lead to high exergy destruction factors even in presence of small $\Delta \mathrm{T}$ between the fluids. This concept, although intuitive, is expressed by $\varsigma$ in quantitative terms. Several other aspects could be analysed, by creating "exergy efficiency destruction maps", i.e. deriving diagrams where $\varsigma$ is plotted versus the different inlet and outlet temperatures.

\subsection{Other cost influencing aspects and innovative representations}

Another relevant aspect for the diagnosis of existing HENsand the understanding of improvement potential is related with technical and economicfeasibility of heat exchangers. According to the method presented in section 3.2, the required number of shells rapidly increases with the "temperature cross" that is, referring to the notation adopted in Fig. 
6 , the difference " $\mathrm{T}_{4}-\mathrm{T}_{2}$ " (when positive). The purchase and installation cost of heat exchangers can be usually calculated by the following expression:

$$
\mathrm{Z}_{\mathrm{HE}}=\mathrm{a}+\mathrm{b} \mathrm{N}_{\mathrm{s}}\left(\mathrm{A} / \mathrm{N}_{\mathrm{s}}\right)^{\mathrm{c}}
$$

Typical figures are " $a=5,000$ EUR" for utility exchangers and " $a=10,000$ EUR" for heat recovery units, " $b=340$ EUR" and " $c=0.8$ ". Then, limiting the number of shells and units is evidently important.

In order to refine the concepts discussed in the previous sub-section with such techno-economic considerations, a new "heat loads plot" can be considered. Let us assume to plot the temperature change experienced by each stream versus its heat capacity flow rate $\overline{\mathrm{G}} \overline{\mathrm{c}}$; ; as usual with the composite curves, let us assign a negligible role to the location of a stream along the horizontal axis. As evident in Fig. 7, the representation of each stream, assumed at a constant $\bar{G} \overline{c_{p}}$ and with a temperature variable between $T_{i}$ and $T_{o}$, identifies a rectangle whose area represents, at adequate scale, the heat load on the stream. Once plotted a distinct rectangle for each individual stream, any network can be represented by shifting horizontally the rectangles so as to identify the actual matches; in Fig. 7 a representation of the existing HEN is provided.

Evidently Fig. 7 already reflects the disaggregation of streams, based on the actual network configuration; for instance, stream 6 is not presented as unique, but splitted into $6 \mathrm{a}, 6 \mathrm{~b}, 6 \mathrm{c}$ and $6 \mathrm{~d}$ (the latter being not represented because coupled with the cold utility). Then, a different plot can be drawn, where all streams have their heat load graphically represented as a unique entity; this modified representation is given in Fig. 8.

In order to allow for an easier interpretation of Figg. 7 and 8, we may observe that:

- $\quad$ a reduction in the number of units could be achieved when, basing on Fig. 8, we identify couples of rectangles with similar areas and temperature levels compatible with heat transfer. When, on the contrary, heat recovery is achieved by overlapping a large rectangle with two or more small rectangles, the number of units will increase;

- in a generic,desirable situation like that presented on the left in Fig. 9.a (and not referring to the current case study), where for a hot stream (stream A) with a high heat load we find a cold stream (stream B) with comparable heat load and heat capacity rate, we should also pose our attention on the maximum temperature range covered by a unique match. Although promising in terms of number of units, the match Stream A Stream B (Scenario 1 in the figure) is very critical due to the large temperature cross; matching Stream A with several cold streams (three in Fig. 9, that are Streams C, D and E) could lead to the more promising Scenario 2, which requires 3 heat exchangers, each with a simpler design and a lower number of shells.

In theory, basing on the heat loads plot a simple heat recovery process could be threaten like a sort of "modified Tetris game”. In the conventional Tetris game, pieces should fill the empty spaces; here, once $\Delta \mathrm{T} / 2$ shifts upwards for cold streams and downwards for hot ones have been imposed, a full heat recovery scenario would emerge from a best overlap amongthe different streams. In this paper the heat loads plot has been just introduced to clarify a basic implication of Eq. 29: the inclusion of heat exchangers resulting in a very high temperature cross and, consequently, in a high number of shells, should be accurately avoided because of both their higher cost $\mathrm{Z}_{\mathrm{HE}}$ (see Eq. 29) and their undesirable major complexity.

\section{Bottom-up approach to plant retrofit}

In the previous sections the examined system was studied in-depth by: 
- analyzing and diagnosing a MER configuration, which could represent a theoretical target for a bottom-up improvement of the existing network;

- $\quad$ diagnosing the existing HEN by the light of the results presented in Figg. 5 and 7.

Also, the new instruments presented in section 4.1 and 4.2 offer us the opportunity for an illuminate improvement of the existing network. It is well known [14] that the topology changes for network's retrofit can essentially consist of:

1. Resequencing, i.e. reversing the order of two exchangers;

2. Repiping, i.e. changing one of the matching streams in a heat exchanger;

3. Adding a new match;

4. Splitting a stream, thus reducing the load on a stream involved in the pinching match (the match where the network pinch is located).

\subsection{Identification of retrofit topologies}

A number of topologies were identified, and for each of them the number of topology changes needed to pass from the existing HEN to the examined topology is indicated with $n^{\Delta^{\text {top }}}$. The possible number of retrofit topologies is very high; because of the didascalic/methodological scope of this paper, the selected topologies were obtained by implementing different possible "topology changes" (i.e. resizing in one case, repiping in one case, adding new matches in four cases and splitting streams in one case). The new matches to be included or the streams to be splitted were identified basing on the results emerged in section 4.1 (see also Fig. 5): the most critical heat exchangers in the network are the A and L, because of their sub-optimal use of the available driving force within the "highly constrained region". Hence, the definition of retrofit topologies was primarily oriented to reduce the $\Delta \mathrm{T}$ on these exchangers and to better exploit the energetic potential of high grade heat (above $200^{\circ} \mathrm{C}$ ) released by "stream no. 9". The experience of the analyst is determinant in this phase: the retrofit topologies, in fact, do not result as "unique possible options" from a rigorous optimization, but are derived by a conceptual analysis, basing on the emerged criticisms of the existing HEN. The following networks are examined:

- Solution no. $1\left(n^{\Delta^{\text {top }}}=0\right)$ : the surface of Heat Exchanger E (HE E, see Fig. 2) is increased, so as to achieve a $\Delta \mathrm{T}_{\min }=10^{\circ} \mathrm{C}$. HE E then pre-heats stream 4 to a higher temperature and the load on the exchanger "Hot UtilityStream 4" (below indicated as HU-4 match) is reduced. The cold inlet temperature to HE D will be increased , thus reducing the driving force for heat transfer and requiring some additional area;

- Solution no. 2 ( $\left.n^{\Delta^{\text {top }}}=1\right)$, see Fig. 10.a: a new match is added between streams 9 and 4 (i.e. a 9-4 match), limited by the " $\Delta \mathrm{T}_{\min }=10^{\circ} \mathrm{C}$ " constraint on the cold side;

- Solution no. $3\left(\mathrm{n}^{\Delta^{\mathrm{top}}}=2\right)$, see Fig. 10.b: the HE B is repiped to match stream 3 with stream 9, rather than with stream 2. The heat exchange area of HE A increases and the load on HU-1 reduces. A new match between streams 3 and 6 is needed to pre-heat stream 3 up to $117^{\circ} \mathrm{C}$;

- Solution no. $4\left(n^{\Delta^{\text {top }}}=2\right)$, see Fig. 10.c: a new 9-4 match is added, limited by the need to lead stream 8 to its target temperature. Stream 8 is pre-heated by a new 2-8 match; small $\Delta \mathrm{T}_{\min }$ violations are allowed for;

- Solution no. $5\left(\mathrm{n}^{\Delta^{\mathrm{top}}}=2\right)$, see Fig. 10.d: similar to solution no. 4, but with stream 8 pre-heated by a new match with stream 6 . The higher heat capacity rate of stream 6 allows for a higher preheating temperature; 
- Solution no. $6\left(\mathrm{n}^{\Delta^{\text {top }}}=1\right)$, see Fig. 10.e: a new 9-3 match is added, shifting to a lower temperature range HE B and increasing the area of HE A, finally reducing the load on HU-1;

- Solution no. 7 ( $\left.n^{\Delta^{\text {top }}}=5\right)$, see Fig. 10.f: streams 3 and 8 were pre-heated by two low rate streams derived by splitting stream 6. The HE B is excluded from the lay-out. Stream 9 is splitted in two streams, matched with streams 3 and 8 to lead them to their target. The ratio between the heat capacity rates of the splitted streams was calculated, basing on the load of the matching streams; the values obtained are presented in Fig. 10.f.

Only the tools related to the qualitative analysis of "heat transfer driving force" in the HEN, presented either in Fig. 5 or in Fig. 7, may concur to support the analyst in the definition of a set of retrofit topologies. The other original tools presented earlier in this paper, and in particular the "exergy destruction factor", the "modified Bath formula" and the detailed $\mathrm{N}_{\mathrm{s}}$-based cost expression (see Eq. 29)are all to be used in a "quantitative evaluation phase", presented in the next subsections.

\subsection{Maximization of energy savings for the examined retrofit topologies}

For each retrofit topology the energy saving can be easily maximized applying the tick-off heuristics, i.e. maximizing the capacity of each heat exchanger while maintaining " $\Delta \mathrm{T}>\Delta \mathrm{T}_{\min }$ ". In Fig. 10.a-f the heat loads expressed in MW and the topology changes can be easily identified; these "maximum energy saving" retrofit topologies, plotted in Fig. 10.a-f, should not be confused with the MER design presented in Fig. 3. Once maximized the energy recovery for each topology, it is possible to get an intuitive representation of the obtainable results by plotting the heat exchanger area versus the energy saving, as made in Fig. 11. As expected, the topologies achieving higher energy savings also require higher heat transfer areas. Let us observe, however, that the solution with the highest $\mathrm{n}^{\mathrm{t}^{\text {top }}}$, that is the no. 7, resulted less efficient than solution no. 3, achieving the same energy saving with a slightly higher heat transfer area. Also, because of the higher number of topology changes, it may be expected that a higher fraction of the overall heat transfer area is represented by "new area", i.e. that major changes will be required, resulting in a higher retrofit cost; this result will be verified below.

The "energetic equivalence" between the lay-outs no. 3 and no. 7 is an obvious consequence of network's structure; both these solutions, in fact, debottleneck a same region of the network, allowing to maximize thermal integration between streams 1 and 2 .

\subsection{Relaxation of the "Maximum energy savings" retrofit topologies}

Let us focus on another aspect. As said, the retrofit solutions presented in Fig. 10.a-f have been designed regardless of the existing network, i.e. assuming to fully replace the heat exchangers where some change (either in terms of capacity or involved streams) occurs. This approach is non-realistic. Relaxation is here intended as the process that modifies a "maximum energy saving - high cost or high-complexity" design into a more "feasible" network, eventually characterized by a less-than-maximum energy saving but lower cost and/or complexity. Relaxation should be always pursued, at some extent, in order to achieve significant reductions in retrofit cost by partially avoiding the dismission of existing facilities; the analyst, however, should be always aware of the associated penalties in terms of energy saving reduction.

Let us exploit the understanding of the retrofit problem acquired in previous sections, plotting on a 3-vertices polygon the main results associated with the solutions from 2 to 7 (solution no. 1 did not involve any topology change). In Fig. 
12 for each solution the changes in the total area, in the total number of shells and in the total exergy destruction are presented in normalized terms (with respect to the values assumed in the existing network), according to the following expressions:

$$
\begin{gathered}
\Gamma_{1}=\frac{\sum_{\substack{\text { heat } \\
\text { exchangers }}} \Delta \mathrm{N}_{\mathrm{s}}}{\left(\mathrm{N}_{\mathrm{s}}\right)_{\substack{\text { existing } \\
\text { network }}}} \\
\sum_{2}=\frac{\sum_{\substack{\text { heat } \\
\text { exchangers }}} \Delta(\zeta \mathrm{Q})}{\left(\sum_{\substack{\text { network } \\
\text { heat }}}\right)_{\text {existing }}} \\
\Gamma_{3}=\frac{\Delta\left(\frac{\mathrm{Q}}{\mathrm{K} \cdot \Delta \mathrm{T}_{\mathrm{lm}}}\right)}{\left(\sum \frac{\mathrm{Q}}{\mathrm{K} \cdot \Delta \mathrm{T}_{\mathrm{lm}}}\right)_{\text {existing }}^{\text {network }}}
\end{gathered}
$$

Although these parameters are represented in Fig. 12 with values ranging between 0 and 1 , some of them $\left(\Gamma_{1}\right.$ and $\left.\Gamma_{3}\right)$ could be, in general, also higher than 1. With respect to the three parameters plotted, Eq. 30-32 and Fig. 12 suggest us that:

1. The higher is $\Gamma_{1}$ for a retrofit topology, the higher is the number of additional shells required to achieve its maximum energy saving. Topologies associated with very high $\Gamma_{1}$ values evidently include some heat exchangers with a critical design (because of a very large temperature-cross), which require an appropriate relaxation;

2. The higher is $\Gamma_{2}$ for a retrofit topology, the higher is the reduction in the overall exergy destruction. Among the three parameters plotted in Fig. 12, this is the only one with a value intrinsically lower than 1: values higher than 1 , in fact, would indicate that HEN retrofit has produced an overalldecrease in energy consumption higher than the exergy destruction rate (i.e. the energy saving potential) of the existing network (evidently meaningless);

3. The higher is $\Gamma_{3}$ for a retrofit topology, the higher the additional heat transfer area to be installed. The topologies associated with very high $\Gamma_{3}$ values may be extremely critical as concerns the capital investment for retrofit; in such cases the relaxation should be primarily oriented to reduce the capacity of very-low- $\Delta \mathrm{T}_{\mathrm{lm}}$ heat exchangers.

Typically, however, the topologies that achieve a high $\Gamma_{2}$ are also characterized by high values of $\Gamma_{3}$ and/or $\Gamma_{1}$; in fact, most of the triangles in Fig. 12, that represent the different solutions (i.e. retrofit topologies), do not intersect each other. Some information may be derived from the shape of triangles: those characterized by relatively high $\Gamma_{2}$ values and relatively low $\Gamma_{1}$ and/or $\Gamma_{3}$ values refer to the most promising solutions. This diagram, however, should not be considered as a "tool to select the best retrofit topology", because a detailed cost analysis is required for this scope; it rather represents "a tool suggesting the best relaxation strategy for each topology".

Of course, Fig. 12presentsresults that areavailable to the analyst also in tabular form; in particular, for each aspect $\left(\mathrm{N}_{\mathrm{s}}\right.$, $\varsigma \mathrm{Q}$ and A) the attention should be focused on the most critical values, as shown for instance for the solutions no. 2, 3 and 4 in Table 2. Basing on Fig. 12 we may observe that: 
- Solutions no. 3 and 7 are extremely critical in terms of number of shells, in particular as concerns the heat exchangers A, very largely sized and with a high temperature cross, and L (see Table 2). Relevant efforts should be made to produce relaxed lay-outs with reduced temperature cross on these most critical heat exchangers;

- Solutions no. 3 and 7 are also critical in terms of increased area. The slightly higher energy savings achieved (see the triangle vertexindicating $\Gamma_{2}$, where these two lay-outs emerge as the most efficient) will be surely "paid" by a much more costly lay-out;

- Since for solutionno. 4 no criticism exists as concerns the number of shells, for thistopology the relaxation could be essentially oriented to maintain constant the value KA for some heat exchanger, in order to avoid dismissing or repiping it.

Figure 12 offers an innovative and more comprehensive representation, with respect to the conventional diagram presented in Fig. 11; the former plot introduces a third element, the number of shells, absent in the latter. Why exergy destruction was used as a criterion, and not energy saving rate?Actually only exergy destruction, and not energy saving rate, can be accompanied by a numerical list of the individual contributions from any heat exchanger: energy saving, in fact, forms at "overall network" level, while an exergy destruction rate can be defined for each individual heat exchanger, thus quantifying the scope for its improvement. Relaxation is usually oriented to overcome some specific limits/problems associated with a certain heat exchanger: recognizing the contribution from any heat exchanger to the overall exergy destruction becomes essential to identify the most appropriate relaxation routes.Exergy destruction is not only available in aggregate terms, i.e. in terms of $\sum_{\text {heat exchangers }} \varsigma \mathrm{Q}$, but may be accompanied by notes, in tabular form, on the specific $\zeta$ value for each heat exchanger. As the exergy destruction factor $\varsigma$ provides intuitive information on the efficiency of heat transfer processes, a list of $\zeta$ values could support the analyst in recognizing the most efficient relaxation strategies (as said in Section 4.2).

Because of the explanatory objective of this paper and basing on the above analysis, a small number of relaxed solutions were examined, that are listed below:

a. Relaxation of solution no. 2:

- $1^{\text {st }}$ relaxation: assume a constant KA for the heat exchanger D (i.e. assume not to replace it). By comparing Fig. 10.a and Fig. 2 we may observe that $\Delta \mathrm{T}_{\min }$ on this heat exchanger has been reduced (stream no. 4 is at higher temperatures than in the existing HEN); then, assuming not to replace HE D a reduction will result in the heat rate $\mathrm{Q}(\mathrm{D})$, passing from $29.3 \mathrm{MW}$ to $27.4 \mathrm{MW}$. The energy supplyby hot utilityat the HU-4match will slightly increase (by $1.9 \mathrm{MW}$ ), because of the lower outlet temperature $\left(375.7^{\circ} \mathrm{C}\right)$ of stream no. 4 from the HE D. The existing HE D will be conserved, achieving a significant reduction in the retrofit cost;

- $2^{\text {nd }}$ relaxation: since the solution no. 2 led, in its "maximum energy saving" design, to a high temperature cross at the HE $\mathrm{L}$ resulting in a number of shell $\mathrm{N}_{\mathrm{s}}(\mathrm{L})=5$, let us increase the outlet temperature $\mathrm{T}_{9, \mathrm{o}}$ at the new 9-4 match and the capacity of this heat exchanger, so as to reduce the temperature cross and the number of shells of HE L. Of course, the inlet temperature of stream no. 4 at HE D will be reduced as a consequence. Differently than the previous relaxation strategy, here a gradual approach could be assumed: depending on whether we assume to reduce the number of shells $N_{s}(L)$ to 4,3 or 2 , the capacity of the new 9-4 match will gradually decrease and the $\Delta \mathrm{T}_{\operatorname{lm}}$ on heat exchanger $\mathrm{D}$ increase. These 
interactions are properly kept into account during the simulation of this relaxed solution, whose results will be presented in the next section; most of the heat exchangers remain unchanged, with the same size, inlet and outlet temperatures presented in Fig. 10.a;

b. Relaxation of solution no. 3:

- $1^{\text {st }}$ relaxation: this topology, whose unrelaxed configuration was presented in Fig. 10.b, includes tighten constraints on the new 9-3 match and on HE L. Due to the very high temperature cross on HE A (which has significantly increased its size, with respect to the existing HEN), in the unrelaxedscheme it resulted to have 16 shells: such a design is evidently unrealistic and of no technical interest. Let us assume to slightly increase the outlet temperature $\mathrm{T}_{2, \mathrm{o}}$ of stream no. 2 at the HE A (whose capacity decreases) so as to gradually reduce its number of shells down to 3. As far as the capacity of HE A decreases, the hot utility will supply to stream 1 an additional heat rate to lead it to its target temperature. The proposed relaxation strategy has no influence on the design of the rest of the network, where all the remaining heat exchangers maintain the same size, inlet and outlet temperatures presented in Fig. 10.b;

c. Relaxation of solutions no. 4 and 5:

- $1^{\text {st }}$ relaxation: let us assume to maintain the same heat exchanger D already installed in the existing HEN; a significant reduction in retrofit cost will result, again minor penalties in energy saving being expected due to increased energy supply at HU-4. The $\Delta \mathrm{T}_{\operatorname{lm}}$ at HE D is in fact reduced with respect to the existing HEN (compare Fig. 10.c,d and Fig. 2), and the heat rate will consequently decrease (at fixed KA). The energy penalty can be easily quantified by calculating the outlet temperature of stream4 at HE D; with respect to the $379.6^{\circ} \mathrm{C}$ and $388.6^{\circ} \mathrm{C}$ shown in Figg. 10.c-d, respectively for the solutions no. 4 and 5, $\mathrm{T}_{4, \mathrm{o}}$ equal to $369.6^{\circ} \mathrm{C}$ and $375.5^{\circ} \mathrm{C}$ were respectively found in the relaxed schemes, resulting in a $1.41 \mathrm{MW}$ penalty for the solution no. 4 and a $1.88 \mathrm{MW}$ penalty for the solution no. 5 (these values result as additional fuel supply rate needed at the hot utility to lead stream 4 to its target temperature);

d. Relaxation of solution no. 6:

- $1^{\text {st }}$ relaxation: let us increase the outlet temperature $\mathrm{T}_{9,0}$ of stream no. 9 at the new 9-3 match (that reduces its capacity) so as to reduce the heat transfer area and the number of shells $\mathrm{N}_{\mathrm{s}}$ on heat exchangers A and L (respectively equal to 7 and 8 in the unrelaxed design presented in Fig. 10.e). Gradually increasing $\mathrm{T}_{9,0}$ from $179^{\circ} \mathrm{C}$ (value assumed in the "maximum energy saving" design for this topology and presented in Fig. 10.e) to $208^{\circ} \mathrm{C}$, the sum of the number of shells of HEs A and L decreases from 15 to 6 , while the energy penalty increases up to 3.91 MW. This penalty is related with the additional fuel supply by hot utility needed to lead stream 3 to its target temperature in a new HU-3 heat exchanger.

No specific relaxations were examined for the solution no. 7 because, as said above, this solution reflects the same peculiar aspects of solution no. 3 and the same relaxation presented for solution no. 3 should be adopted (finally achieving similar results).

In Fig. 13 the results are plotted in terms of heat transfer area versus energy consumption rate. The main solutions (i.e. the maximum energy recovery design obtained for the seven retrofit topologies presented in Fig. 10) are identified by a circle; their relaxed lay-outs are indicated with the same marker and an explicative note. Let us consider, for instance, the series associated with solution no. 3 and with its relaxed lay-outs (identified by circular markers in Fig. 13); as the relaxation was oriented to reduce the number of shells of HE A from its original value, $\mathrm{N}_{\mathrm{s}}=16$, down to 3 , each number close to this series indicates the associated $\mathrm{N}_{\mathrm{s}}(\mathrm{HE} \mathrm{A})$. Obviously, the point associated with $\mathrm{N}_{\mathrm{s}}(\mathrm{HE} A)=15$ is very close to the unrelaxed solution no. 3 (indicated in the circle), since a minor relaxation has been made to reduce the number of 
shells from 16 to 15; much larger are the variations for the lay-outs associated with major relaxations (see, for instance, the last circular marker, associated with $\mathrm{N}_{\mathrm{s}}(\mathrm{HE} \mathrm{A})=3$, with a $63400 \mathrm{~kW}$ energy consumption rate and a $14700 \mathrm{~m}^{2}$ total heat exchange area).

Once clarified the meaning of Fig. 13, let us extrapolate from it some information. First, we observe that some hypothetical limit curves were drawn in dotted bold line, associated with different values of $\mathrm{n}^{\text {top }}$ and following the typical trends postulated by Asante and Zhu [3]; these curves were drawn with a slight translation to the left with respect to the convolution of the representative points for the different solutions. The rational of the work by Asante and $\mathrm{Xhu}$, in fact, suggests us to obtain such iso- $\mathrm{n}^{\Delta^{\text {top }}}$ curves by enveloping the most efficient solutions obtainable for a given $\mathrm{n}^{\Delta^{\text {top }}}$.

It could be observed that these curves have a quite similar trendto the "relaxation curves" (i.e. the curves connecting the points associated with schemes derived relaxing a same solution). The significance, however, is completely different. While the iso- $\mathrm{n}^{\Delta^{\text {top }}}$ curves would never intersect each other, in fact, the relaxation curves related to the solutions no. 3 and no. 6 (respectivelyidentified by circular and diamond-shaped markers) actually intersect. That means, although the solution no. 3 can achieve higher energy savings in its "maximum energy saving" configuration (see Fig. 10.b), when strongly modified by relaxation to reduce $\mathrm{N}_{\mathrm{s}}(\mathrm{HE}$ A) it becomes "qualitatively worse" than the analogous relaxed layouts obtainable from solution no. 6; the latter, in fact, achieve the same energy saving with lower heat exchange areas. Let us now focus on the detailed results obtained for the different schemes, in economic terms.

The need for a simultaneous analysis of the three main factors $\varsigma Q, N_{s}$ and $A$ is induced by the form of Eq.29. In Fig. 14.a retrofit cost is plotted versus heat exchange area and energy saving. It can be observed that relaxation allows relevant reductions in retrofit cost as evident, for instance, from the results for the solutions no. 2 and 4 , highlighted in the figure. Looking more in depth at the relaxation of solution no. 4, for instance, we couldalso calculatean average 230 EURsaving per kW thermal penalty, as indicated in Fig. 14.a; similar values could be easily obtained for all the relaxation steps and for any solution. This average 230 EUR saving per $\mathrm{kW}$ thermal penalty results from the ratio between the marginal 278000 EUR reduction in retrofit cost and the marginal $1210 \mathrm{~kW}$ thermal penalty associated with the relaxation of solution no. 4 (see Fig. 14.a).

In order to state whether or not these relaxations are profitable, boundary conditions should be specified and an objective function defined. Let us assume the aromatics plant to be operated 7000 hours per year, and assume to have installed, as hot utilities, boilers with a $90 \%$ efficiency; the cost of natural gas is $0.357 \mathrm{EUR} / \mathrm{Nm}^{3}$. By these data, an average $280 \frac{\mathrm{EUR}}{\mathrm{kW} \cdot \mathrm{y}}$ costper year and per unit capacity is calculated for the hot utility. As concerns the cold utility, assuming to have an evaporative cooler installed, a realistic $6 \frac{\mathrm{EUR}}{\mathrm{kW} \cdot \mathrm{y}}$ unit cost is calculated, resulting from the water consumption for integration.

These utility costs deserve some additional explanation; usually, in fact, costs per unit energy (rather than per year and per unit capacity) are given. For pinch studies in process industry, however, the above units areoftenadopted [14], in order to calculate more easily the payback time of investments: the cost of utilities is expressed in $\frac{\mathrm{EUR}}{\mathrm{kW} \cdot \mathrm{y}}$, to be intended as "additional cost, on annual basis, per additional $\mathrm{kW}$ required to the utility". Let us calculate, for instance, 
the above $280 \frac{\mathrm{EUR}}{\mathrm{kW} \cdot \mathrm{y}}$ fuel cost for the hot utility. Assuming 7000 hours per year operation (a "rectangular load profile" is supposed), $1 \mathrm{~kW}$ additional capacity of hot utility implies $7000 \mathrm{kWh}$ additional heat supply per year; a boiler with a 0.9 efficiency, fuelled by natural gas with a $35800 \mathrm{~kJ} / \mathrm{Nm}^{3}$ low heat value, will consequently consume $786.5 \mathrm{Nm}^{3} /$ year per $\mathrm{kW}$ capacity required to the hot utility. Accounting for the unit cost of natural gas, the $280 \frac{\mathrm{EUR}}{\mathrm{kW} \cdot \mathrm{y}}$ unit cost is finally obtained. The analogous $6 \frac{\mathrm{EUR}}{\mathrm{kW} \cdot \mathrm{y}}$ for the cooling utility can be intended similarly.

Under these assumptions, the simple Payback Time (SPT) of the marginal investment is presented in Fig. 14.b for all the retrofit solutions and their relaxed lay-outs (but the relaxed lay-outs of solution no. 7). The economic viability largely varies from a solution to another; minimum values in the order of 1-1.5 years are almost acceptable, while the worst solutions, achieving SPT in the order of 3.5-4 years, would never be considered as viable options according to the very short payback periods usually expected in process industry.

Let us observe that the least efficient solutions achieve very high SPT (see solutions no. 1 and 4); their relaxed lay-outs have significantly shorter payback periods, but they scarcely exploit the heat recovery potential. As concerns the most interesting solutions, we observe that:

- From an economically non-viable solution, like the no. 2, a smart relaxation strategy can lead to identify convenient lay-outs;

- The relaxation path usually proceeds along an initial region where marginal relaxation is profitable (see descendant profiles of the SPT in Fig. 14.b, identified by descendant arrows) and a final range where any marginal relaxation becomes unprofitable (see ascending profiles in Fig. 14.b, again identified by arrows). Then, when following a certain relaxation strategy, the analyst should be aware of this typical trend and limit the relaxation at a certain extent, so as to maximize or minimize the objective function.

\section{Summary of the multi-approach technique and main results}

In previous sections the multi-approach analysis was applied to an aromatics plant. Being the analysis based on the combined use of existing techniques and on some methodological upgrades, it seemed opportune to describe the different steps directly by applying the techniques to the case study and extrapolating some conclusions.

An overview of the proposed heuristic/interpretative approach is presented in Fig. 15. The algorithm presented in figure is accompanied by comments on the additional capabilities acquired by the analyst at each step; some labels are highlighted (see figure key), to allow for an easier identification of the innovative techniques introduced in this work. When addressing a retrofit problem, the analyst develops preliminary analyses on streams and collects data about the existing HEN (Step 1 in Fig. 15, not examined in this paper). According to the studies presented in Sections 3 and 4, before addressing the retrofit problem the analyst mayidentify a MER design (Step 2-a in Fig. 15), eventually diagnosing it, and perform a diagnosis of the existing HEN (Step 2-b). The in-depth understanding acquired during these analyses as concerns the peculiar energetic (in terms of sub-optimal uses of driving force) and morphological (in terms of complexity of the MER design) issues could reveal useful during the most critical phases, identified as "Step 3" and "Step 4" in Fig. 15.

During the "Identification and evaluation of retrofit topologies" phase (Step 3) the analyst defines a set of topologies; the values of $\mathrm{N}_{\mathrm{s}}, \zeta \mathrm{Q}$ and $\mathrm{A}$, available both in graphical an tabular form, suggest, for each topology, both the main 
criticisms and the improvement directions for the successive phase, "Identification and evaluation of relaxed lay-outs" (Step 4).

With respect to the scheme presented in Fig. 15, the procedure can be eventually simplified. The analyst can decide to by-pass either the "Step 2-a" or "Step 2-b" (or eventually both of them), focusing the attention on the most crucial phases, represented by "Step 3" and "Step 4"; obviously, this could result in major difficulties during the definition of retrofit topologies, because of the poor understanding of thermal inefficiencies and feasible targets.

The proposed procedure can be considered alternative to those based on "optimization algorithms". The former is apparently poorer in terms of rigorousness, being the expertise of the analyst determinant in the evaluation of the different solutions; however, it provides a more complete understanding of the problem, suggesting not only an optimal lay-out, but also several near-optimal ones (which can be identified in Fig. 14.b). The approach is also consistent to a common practice in process industry, where the possibility to determine "good solutions" by flexible approaches is often preferred to the use of more rigorous instruments that identify "optimal solutions".

The main results of the analysis proposed in this work may be summarized as follows:

1. A keen diagnosis of the existing HEN should not be limited to identify network pinches, but should be rather oriented to a complete understanding of the sub-optimal uses of available driving force. In this phase, together with the conventional "driving force plot", other techniques(like the "exergy destruction factors") could be developed to get a more intuitive representation of the heat integration and energy saving potential;

2. A multi-objective diagnosis of a Maximum Energy Recovery design allows the analyst to realize whether it represents an interesting target point for a bottom-un approach to plant retrofit;

3. A detailed thermal modeling is an essential instrument to recognize criticisms and evaluate additional costs. The retrofit cost, in fact, depends not only on the new heat exchange area to be installed, but also on the complexity of HEN structure; this item is of a particular interest when some exchangers have significant temperature crosses, resulting in a high number of shells needed;

4. Once identified, basing on the above arguments, a number of feasible retrofit solutions (each associated with some topology changes), an efficient relaxation of these schemes is determinant to achieve economic viability. The joint evaluation of the heat exchange area, the exergy destruction factors $\zeta$ and the number of shells may offer a determinant support to rationally identify the relaxation paths;

5. Along any relaxation path, the Simple Payback Time follows alternate trends: relaxation initially reveals convenient, but it should be limited to a certain target to avoid an excessive decrease of energy saving that would finally lead to worse economic results.

\section{Conclusions}

An innovative heuristic/interpretative approach was proposed for the retrofit and relaxation of existing Heat Exchanger Networks. The method is based on a combined use of several existing techniques, but it also includes some innovative instruments. Among these original tools, the "heat loads plot" was proposed, which helps the analyst to recognize more intuitively the heat integration potential of process streams. Another innovative approach consists of a modified exergy analysis based on the "exergy destruction factors"; these factors indicate, for each heat exchanger, the inefficiency related with its peculiar temperature profiles.As expected, the diagnosis of the existing HEN allowed to identify, for the examined case study, the most critical sub-optimal uses of the available driving force (i.e. the hot side of HE L and the hot side of HE E), thus suggesting actions for improvement. 
Finally, an innovative spider-type graph was introduced, where the three most cost-influencing factors, i.e. the exergy destruction, the number of shells and the heat transfer area needed, are jointly presented; when a number of retrofit topologies are examined on this graph, preferential relaxation paths can be easily identified for each of them.For the examined case study, the diagram suggested the extreme criticism of solutions no. 3 and 7 both in terms of number of shells and increased heat transfer area: relaxations oriented to reduce the "temperature cross" at heat exchanger A were required to increase the economic viability of these schemes.

The whole procedure was described during its application, step by step, to a well-known case study available in literature; it revealed apparently complex, but efficient in providing the analyst with an in-depth understanding of the specific retrofit problem. The Simple Payback Time was mapped for a large number of schemes (associated with different topologies and their relaxed lay-outs), identifying some general trends as concerns the profitability of retrofit and relaxation process. In particular, more complex topology changes can sometime result in worse energetic or economic results, with respect to the configurations achieved by minor modifications. Also, along a relaxation path there is generally an initial convenience in relaxing the network, but this relaxation process should be interrupted at a certain point, where the marginal reduction in the retrofit cost is lower than the major penalties due to the additional energy consumption.

\section{Acknowledgments}

The author wishes to express his gratitude to Eng. RaffaeleImperato for his precious suggestions during the very early phases of this study.

\section{References}

[1]. T.N. Tjoe, B. Linnhoff, Using pinch technology for process retrofit, Chemical Engineering, 93 (1986) 47-60.

[2]. A. Carlsson, P. Franck, T. Berntsson, Design better heat exchanger network retrofits, Chemical Engineering Progress, 89 (1993) 87-96.

[3]. N. D. K. Asante, X. X. Zhu, An automated and interactive approach for heat exchanger network retrofit, Trans. IChemE, 75 (1997) 349-360.

[4]. S. Ahmad, R. Smith, Targets and design for minimum number of shells in heat exchanger networks, Chemical Engineering Research \& Design, 67 (1989) 481-494.

[5]. A.R. Ciric, C.A. Floudas, A retrofit approach for heat exchanger networks, Computers \& Chemical Engineering, 13 (1989) 703-715.

[6]. E. Rezaei, S. Shafiei, Heat exchanger networks retrofit by coupling genetic algorithm with NLP and ILP methods, Computers and Chemical Engineering, 33 (2009) 1451-1459

[7]. P.S. Varbanov, J. Klemeš, Rules for paths construction for HENs debottlenecking, Applied Thermal Engineering, 20 (2000) 1409-1420.

[8]. R. Nordman, T. Berntsson, Use of advanced composite curves for assessing cost-effective HEN retrofit I: Theory and concepts, Applied Thermal Engineering, 29 (2009) 275-281.

[9]. P. Ruohonen, P. Ahtila, Analysis of a mechanical pulp and paper mill using advanced composite curves, Applied Thermal Engineering, 30 (2010) 649-657.

[10]. R. Smith, M. Jobson, L. Chen, Recent development in the retrofit of heat exchanger networks, Applied Thermal Engineering, 30 (2010) 2281-2289.

[11]. A. Osman, M.I.A. Mutalib, M. Shuhaimi, K.A. Amminudin, Paths combination for HENs retrofit, Applied Thermal Engineering, 29 (2009) 3103-3109.

[12]. K. Matsuda, K. Kawazuishi, Y. Hirochi, R. Sato, Y. Kansha, C. Fushimi, Y. Shikatani, H. Kunikiyo, A. Tsutsumi, Advanced energy saving in the reaction section of the hydro-desulfurization process with self-heat recuperation technology, Applied Thermal Engineering, 30 (2010) 2300-2305.

[13]. B. Linnhoff, D.W. Townsend, D. Boland, A User Guide on Process Integration for the Efficient Use of Energy, Institution of Chemical Engineers, $1^{\text {st }}$ Ed., Rugby, 1982.

[14]. I.C. Kemp, Pinch Analysis and Process Integration, Butterworth-Imprint of Elsevier, Oxford, 2007.

[15]. B. Linnhoff, E. Hindmarsh, The Pinch Design Method for heat exchanger networks, Chemical Engineering Science, 38 (1983) 745-763.

[16]. Pinch spreadsheet NOV06 FINAL, <www.elsevierdirect.com/companion.jsp?ISBN=9780750682602> accessed on 06.11.2010. 
[17]. S. Ahmad, B. Linnhoff, R. Smith, Cost optimum heat exchanger networks. 2. Targets and design for detailed capital cost models, Computers and Chemical Engineering, 14 (1990) 751-767.

[18]. R.W. Serth, Process Heat Transfer - Principles and Applications, C Academic Press - Imprint of Elsevier, Oxford, 2007.

[19]. D.W. Townsend, B. Linnhoff, Surface area targets for heat exchanger networks, Proc. of The IChemE Annual Research Meeting, Bath, April 1984.

[20]. B. Linnhoff, S. Ahmad, Cost optimum heat exchanger networks, Part 1: Minimum energy and capital using simple models for capital cost, Computers \& Chemical Engineering, 14 (1990) 729-750.

[21]. R.A. Bowman, A.C. Mueller, W.M. Nagle, Mean Temperature difference in design, Trans. of ASME, May (1940) 283-293.

[22]. S.J.M. Cartaxo, F.A.N. Fernandes, Counterflow logarithmic mean temperature difference is actually the upper bound: A demonstration, Applied Thermal Engineering, doi:10.1016/j.applthermaleng.2010.12.015.

[23]. R.E. Wales, Mean temperature difference in heat exchangers, Chemical Engineering, 23 (1981) 77-81.

[24]. A. Fakheri, Alternative Approach for Determining Log Mean Temperature Difference Correction Factor and Number of Shells of Shell and Tube Heat Exchangers, Journal of Enhanced Heat Transfer, 10 (2003) 407-420. 


\section{Figure captions}

Fig. 1. Schematic of the aromatics plant.

Fig. 2. Grid diagram of the existing heat recovery network.

Fig. 3. MER design: a. above pinch, b. below pinch.

Fig. 4. Composite curves and enthalpy intervals.

Fig. 5. Driving Force Plot of the existing HEN.

Fig. 6: Temperature profiles for counter-current heat exchangers, with $\mathrm{G} \overline{\mathrm{c}_{\mathrm{p}}}$ : a. finite for both streams, b. infinite for the hot stream, c. infinite for the cold stream.

Fig. 7. Heat loads plot for the existing HEN.

Fig. 8. Heat loads plot with each stream identified as unique.

Fig. 9. Heat loads plot for a virtual case, illustrating the need for minimum temperature cross.

Fig. 10. Grid diagram of the examined topology changes: a. solution no. 2, b. solution no. 3, c. solution no. 4 , d. solution no. 5 , e. solution no. 6 , f. solution no. 7 .

Fig. 11. Conventional representation of the results achieved by the different topologies, when optimized for maximum energy recovery.

Fig. 12. Three-parameters-based evaluation of the examined retrofit solutions.

Fig. 13. Heat transfer area vs. energy consumption for the examined retrofit solutions and their relaxed lay-outs.

Fig. 14.a. Retrofit cost for the examined solutions and their relaxed lay-outs.

Fig. 14.b. Simple Payback Time for the different solutions and their relaxed lay-outs.

Fig. 15. Overview of the proposed heuristic/interpretative approach proposed. 


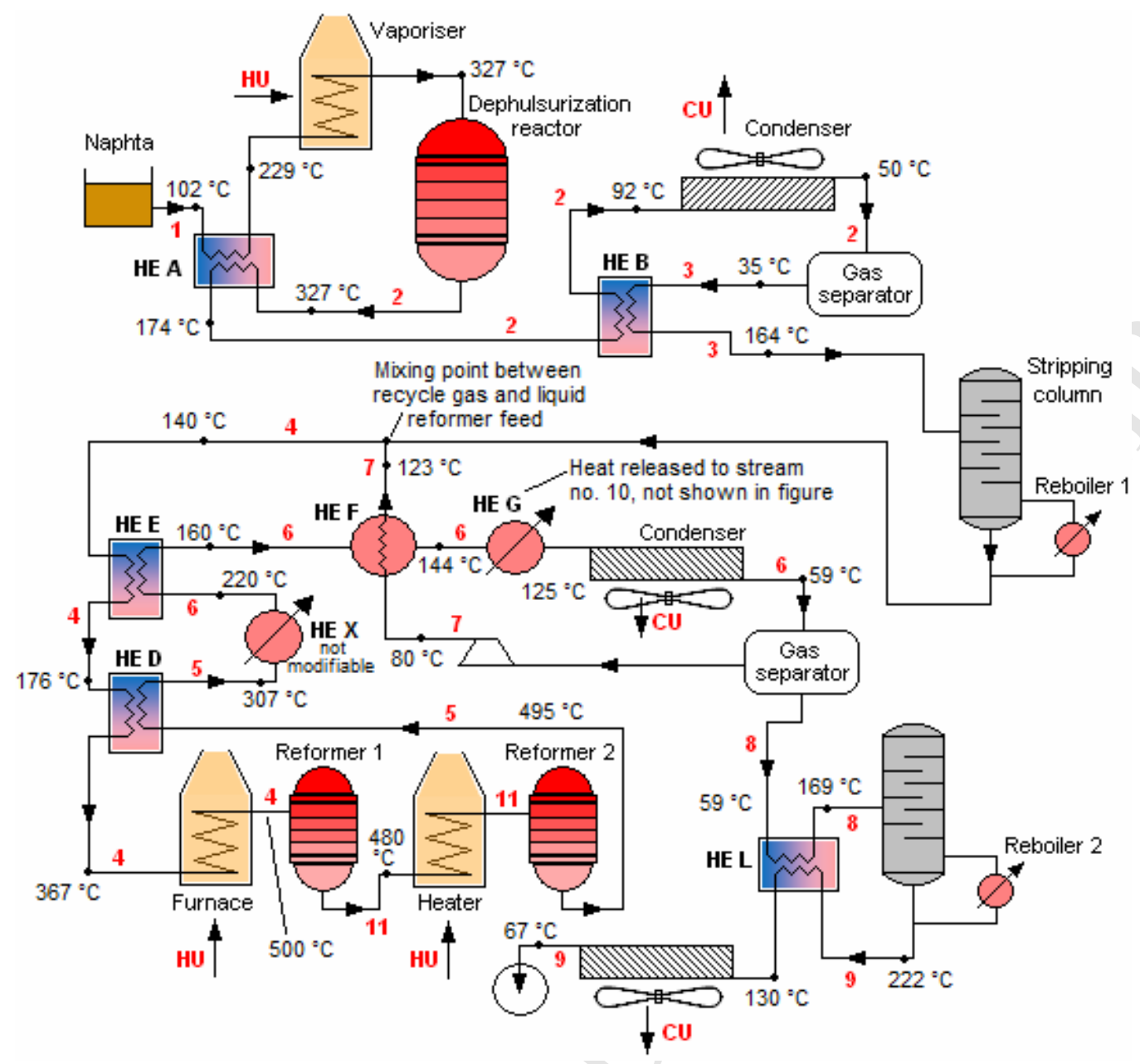

Fig. 1.

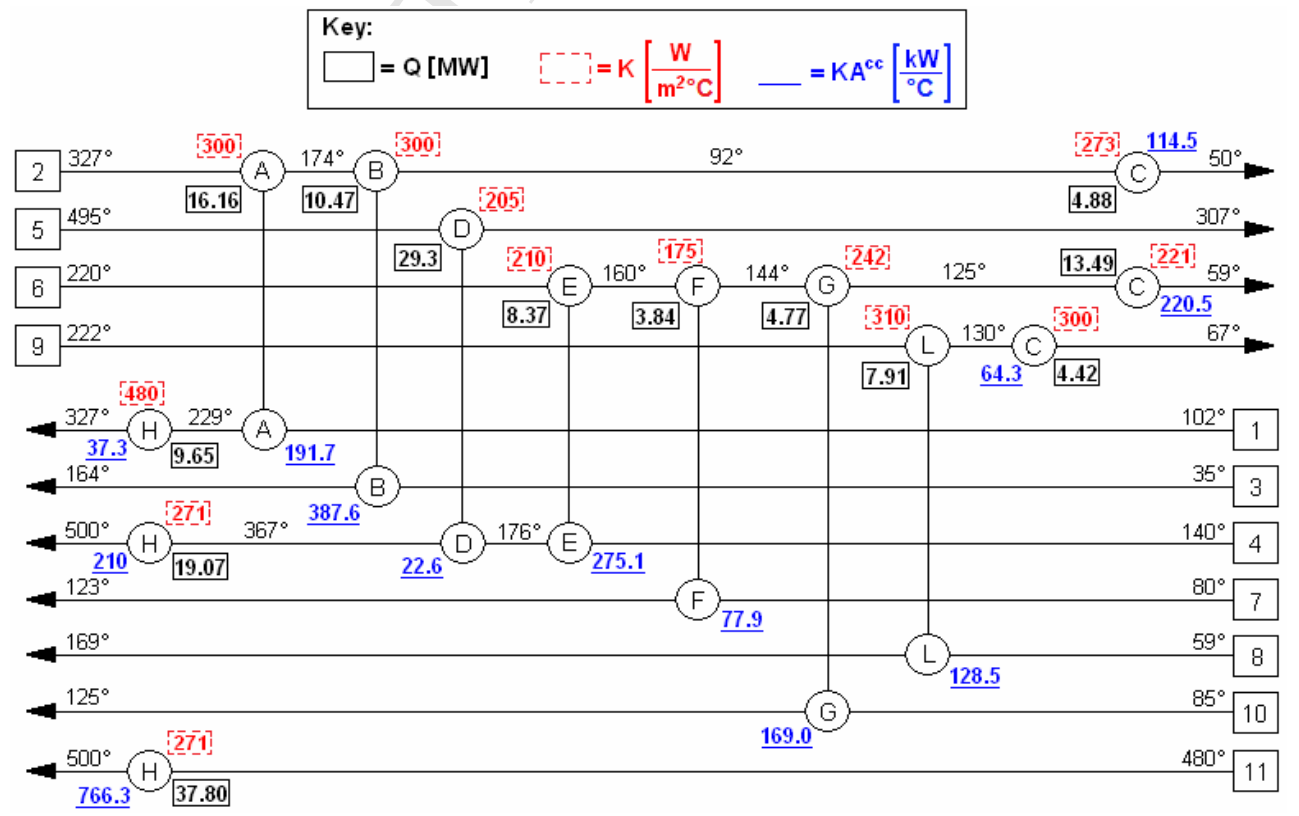

Fig. 2. 


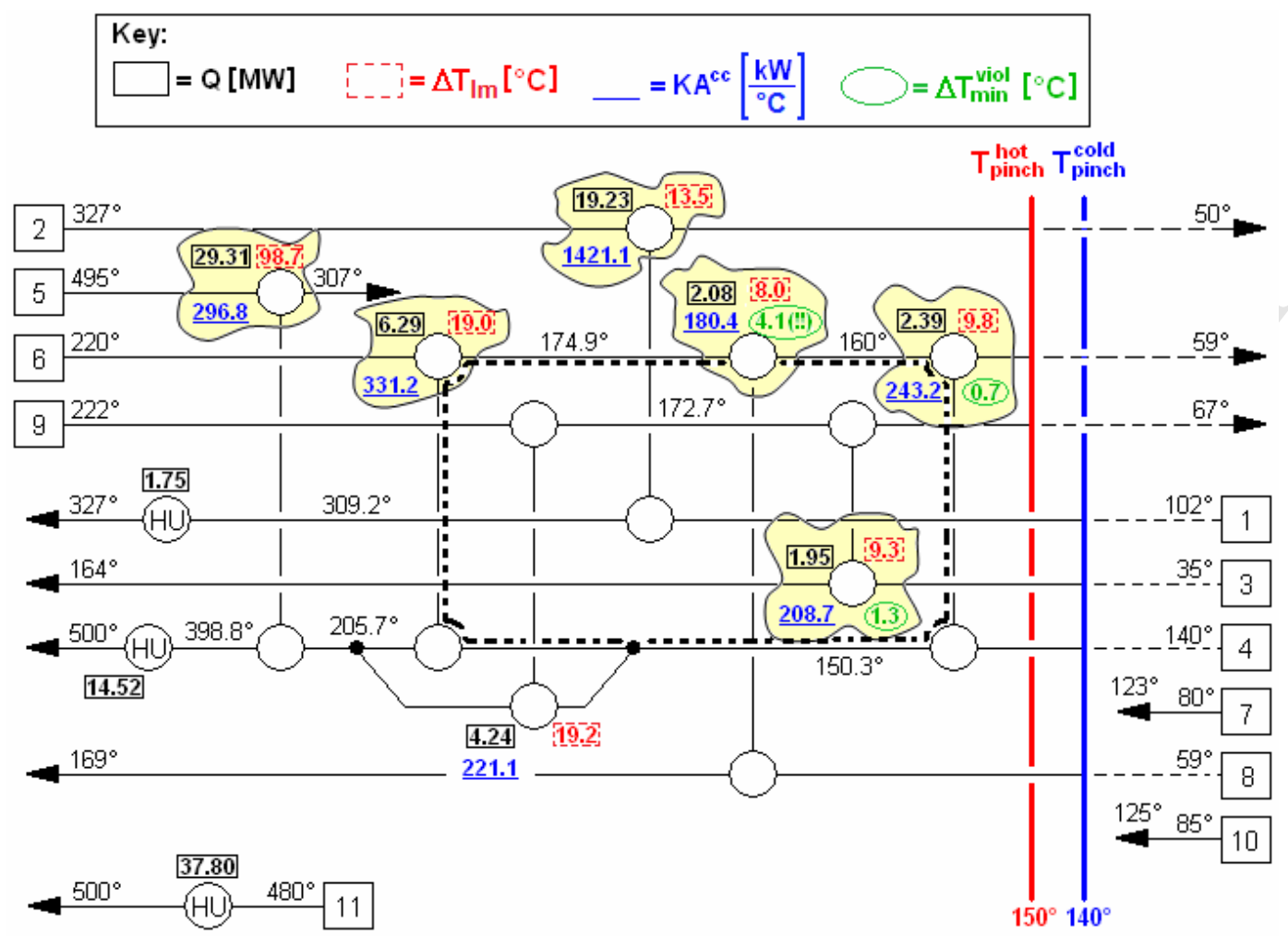

Fig. 3.a.

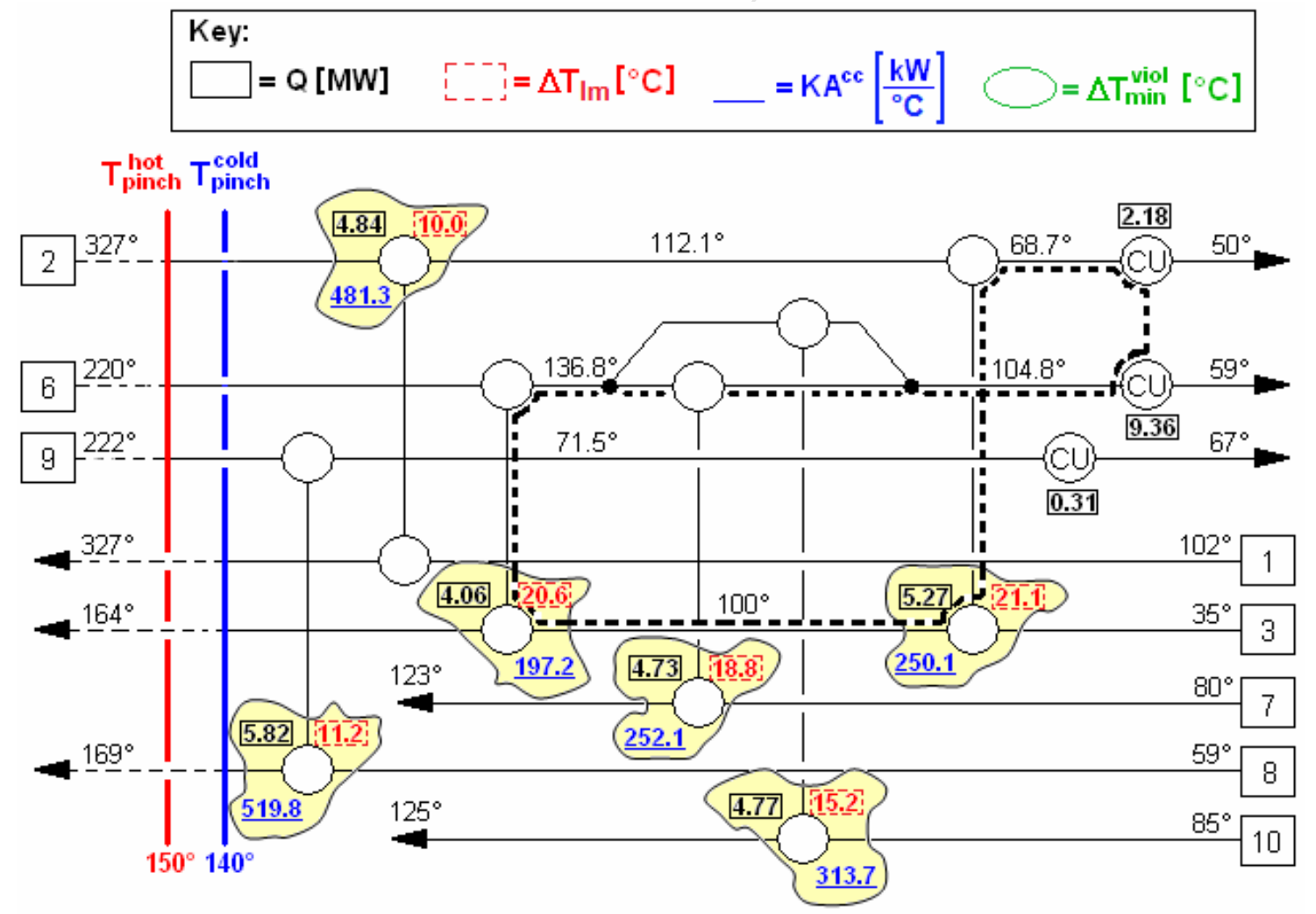

Fig. 3.b. 


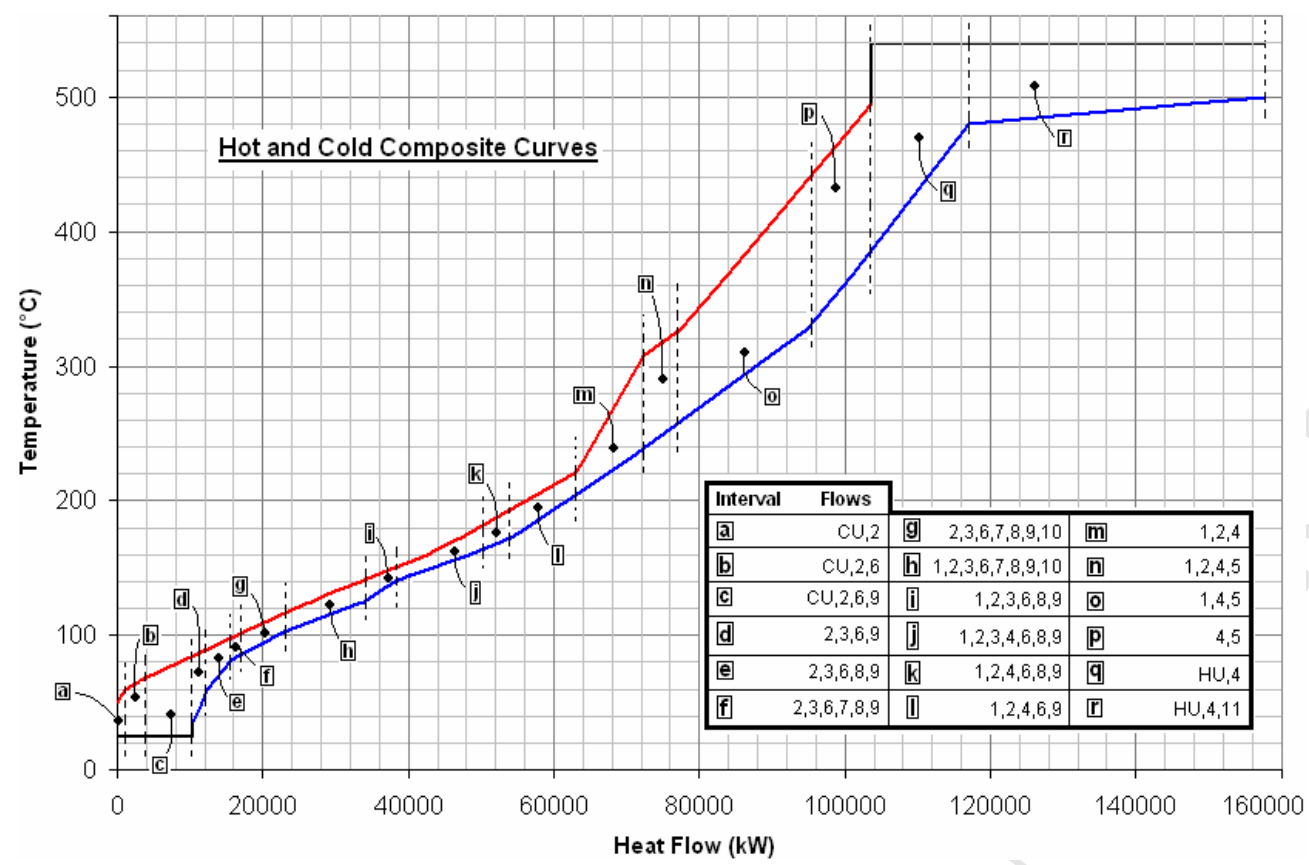

Fig. 4.

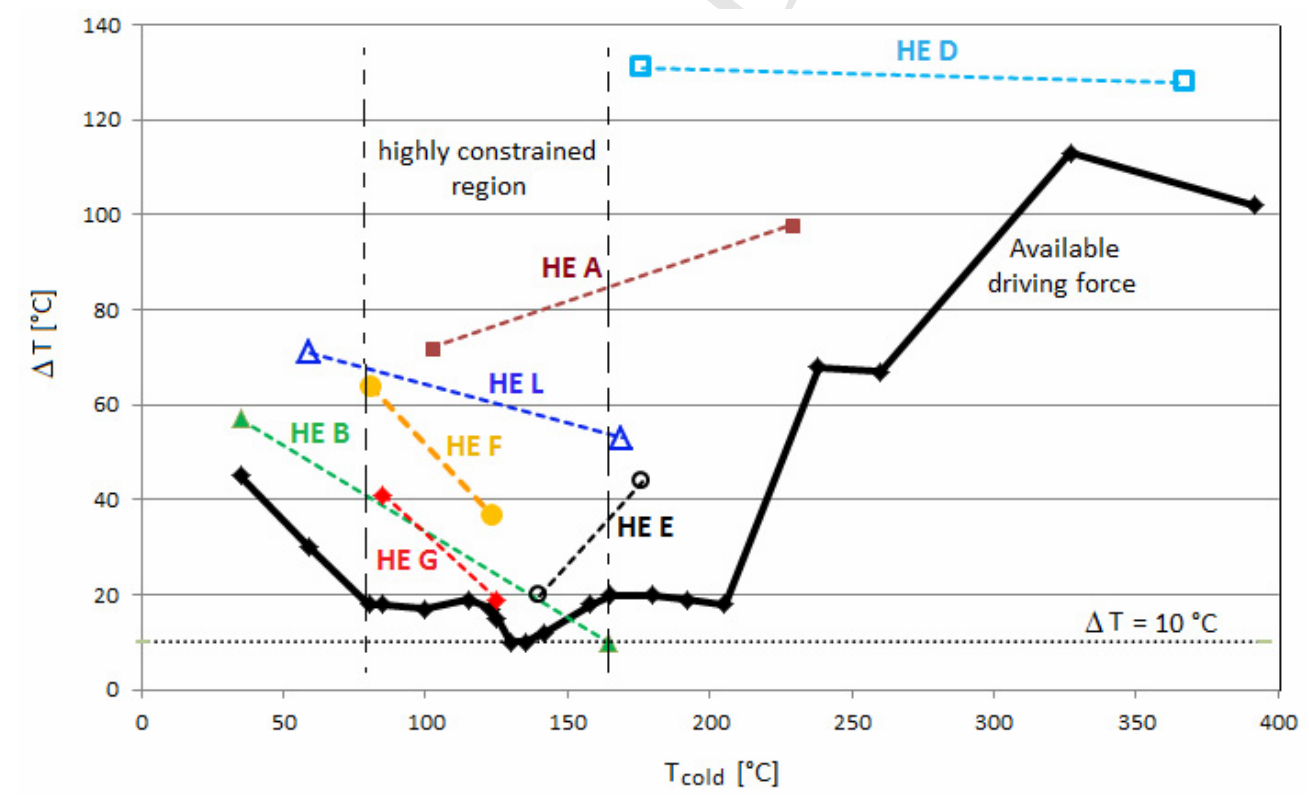

Fig. 5. 


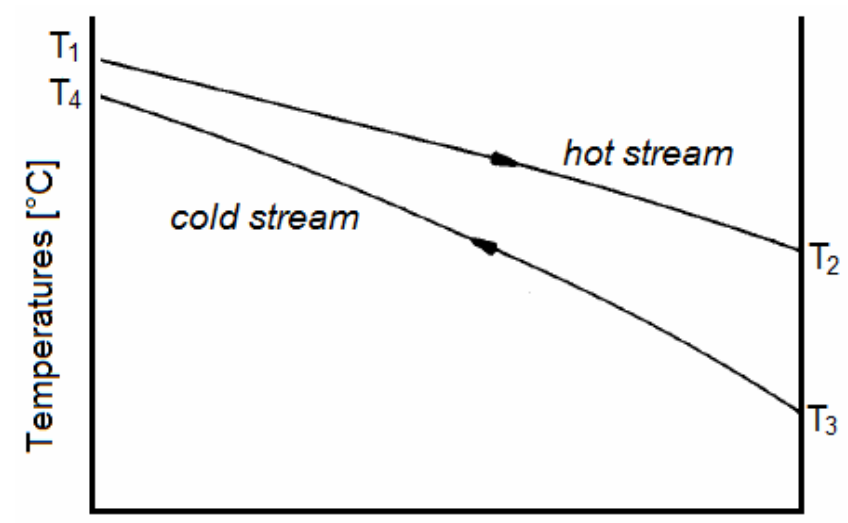

Distance along the exchanger [m]

Fig. 6.a

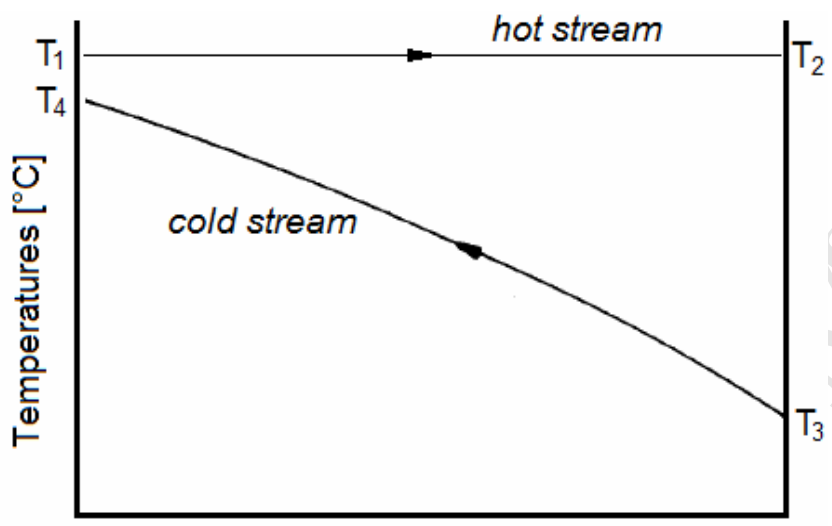

Distance along the exchanger [m]

Fig. 6.b

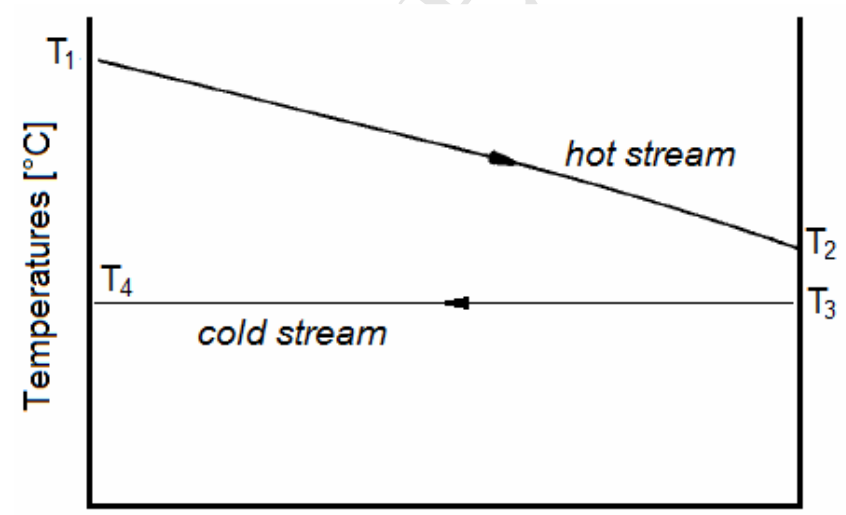

Distance along the exchanger [m]

Fig. 6.c 


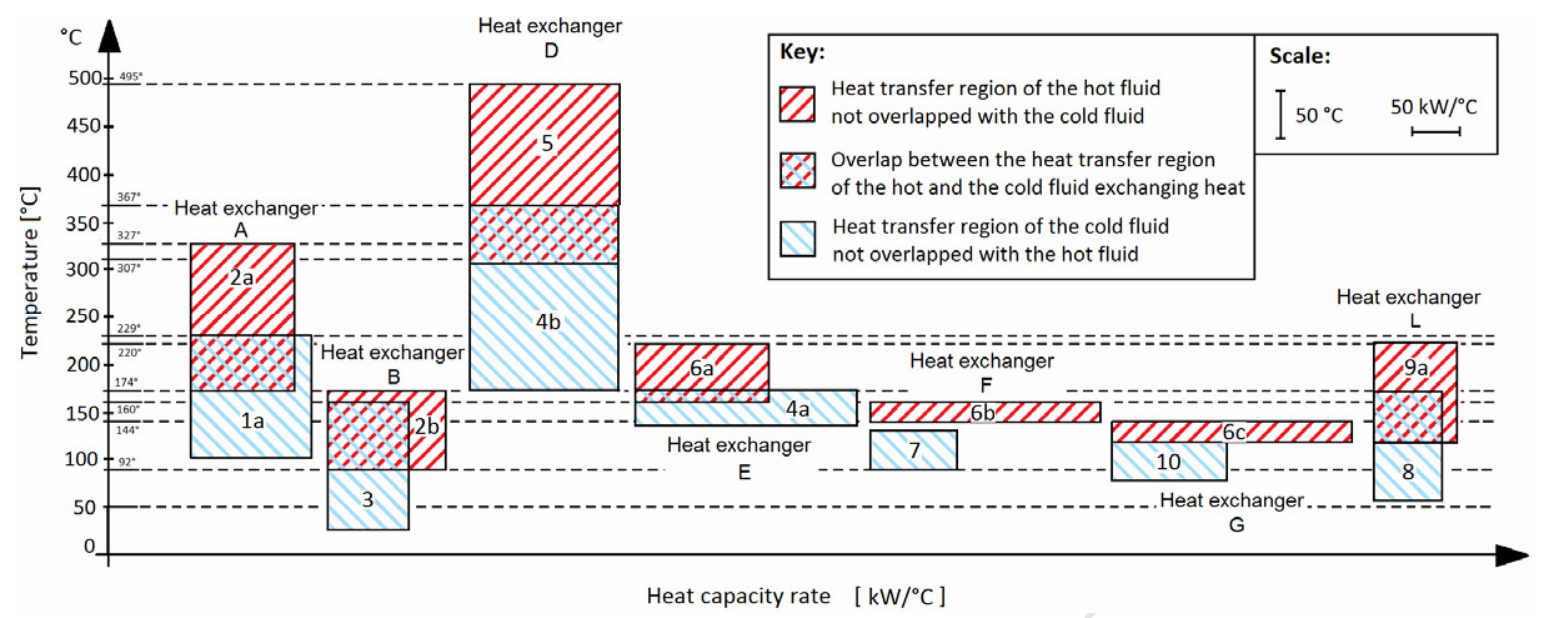

Fig. 7.

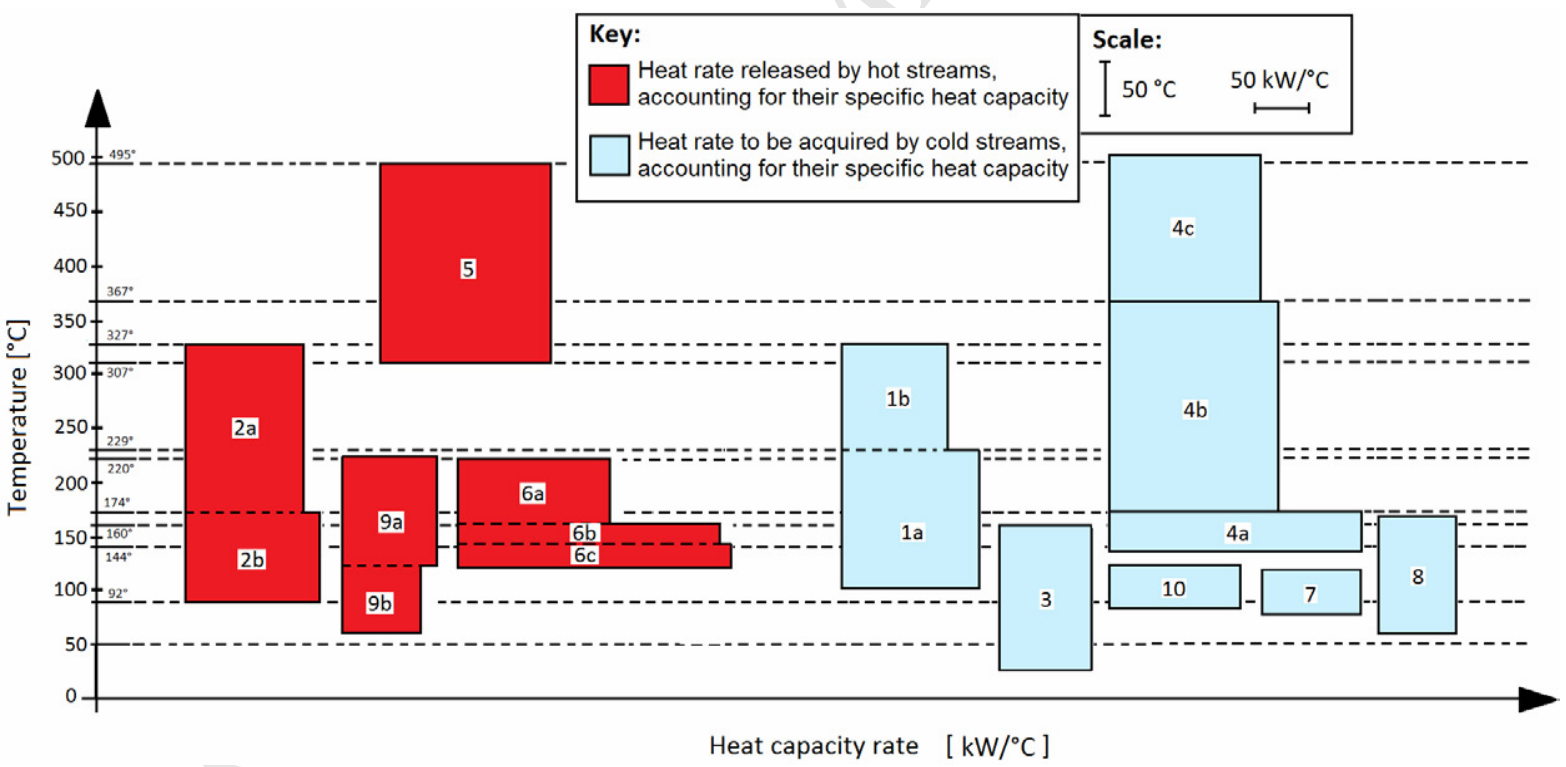

Fig. 8. 


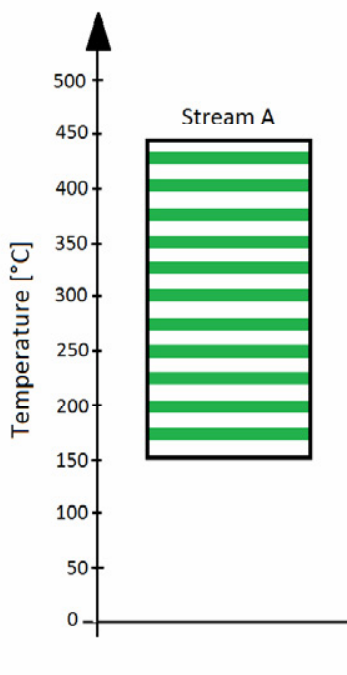

\begin{tabular}{|l|l|}
\hline Key: & Scale: \\
\hline $\begin{array}{l}\text { Heat transfer region of the hot fluid } \\
\text { not overlapped with the cold fluids }\end{array}$ & $\mathrm{T} 50{ }^{\circ} \mathrm{C}$ \\
&
\end{tabular}

$\therefore$ Heat transfer region of the cold fluids not overlapped with the hot fluid

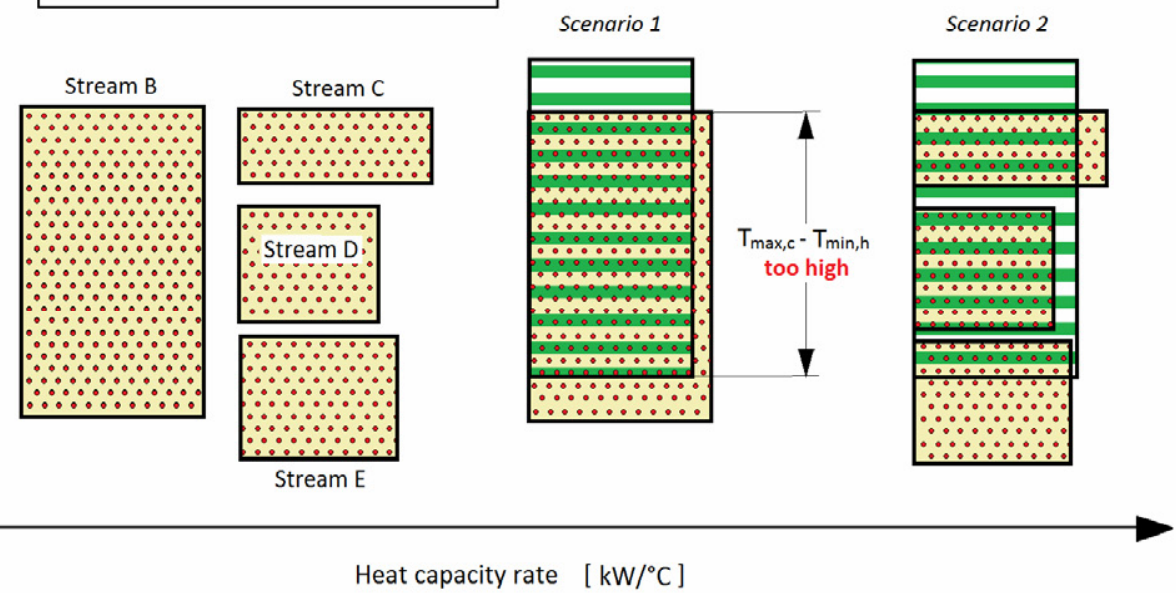

Fig. 9. 


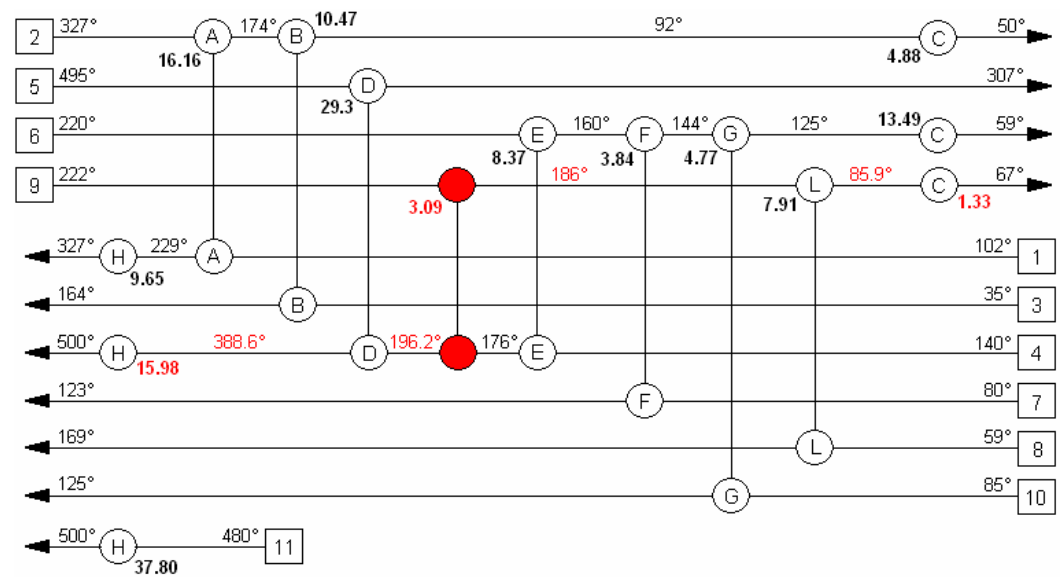

Fig. 10.a

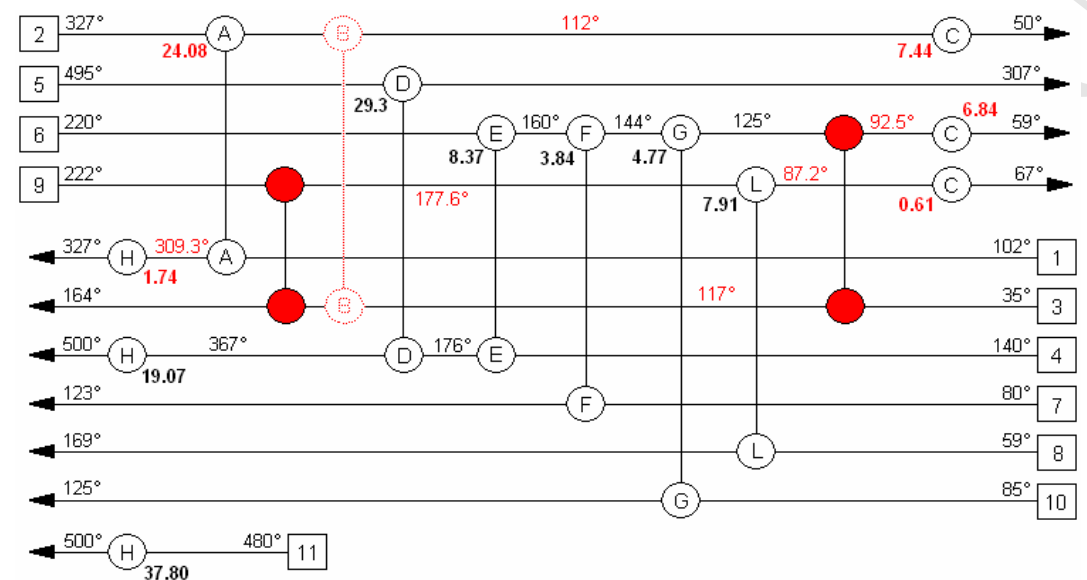

Fig. 10.b

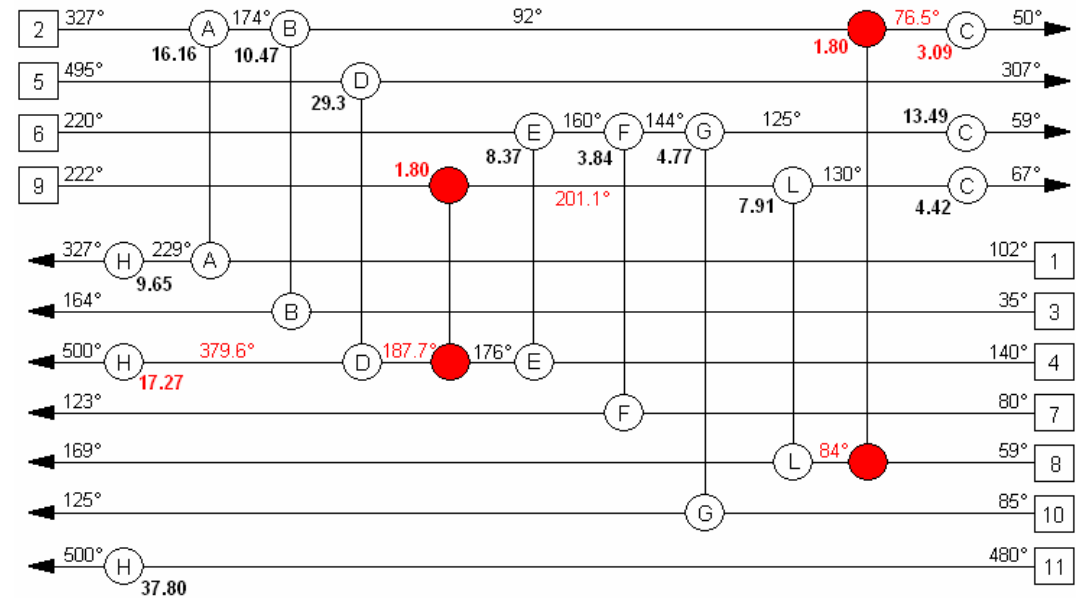

Fig. 10.c 


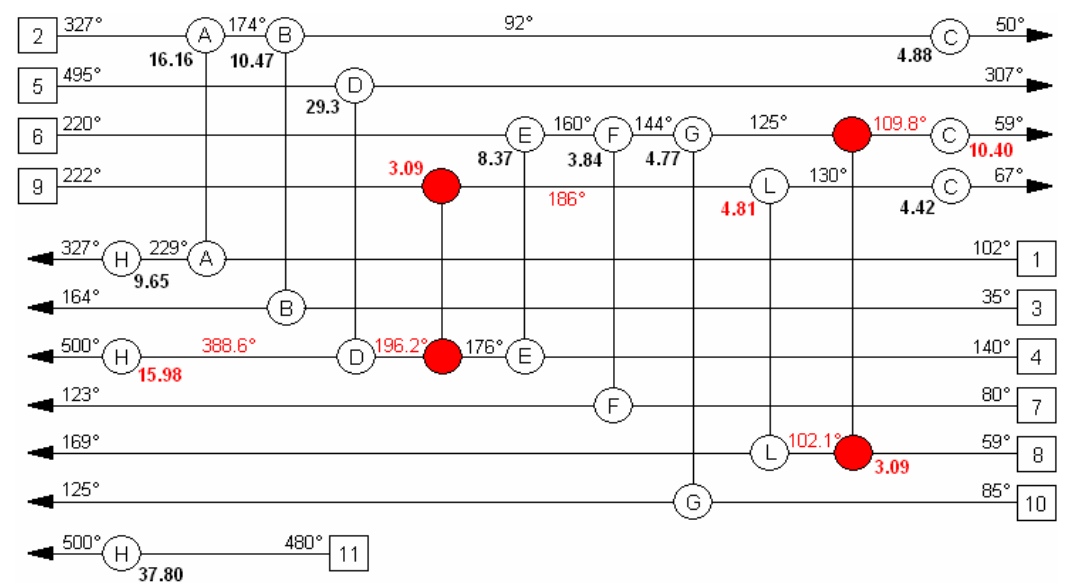

Fig. 10.d

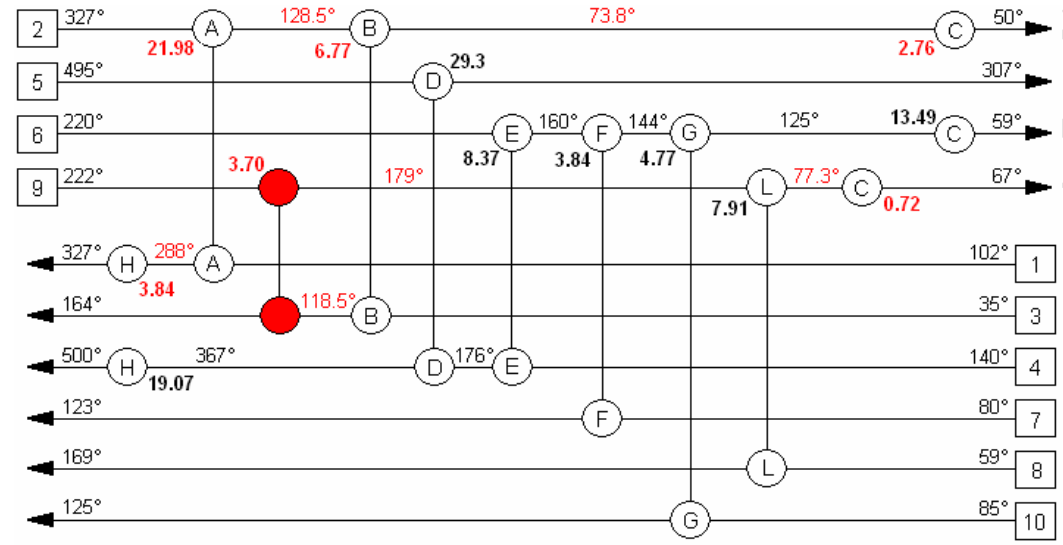

$-500^{\circ}(H) \underset{37.80}{2} \quad 480^{\circ} 11$

Fig. 10.e

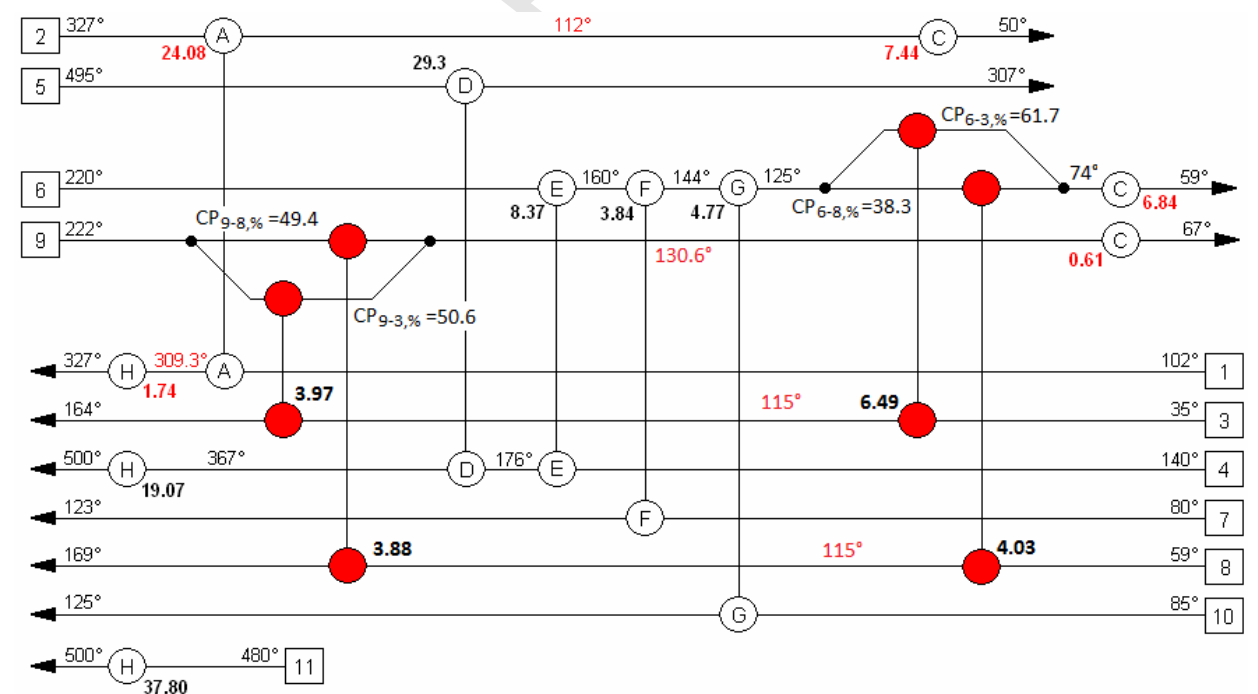

Fig. 10.f 


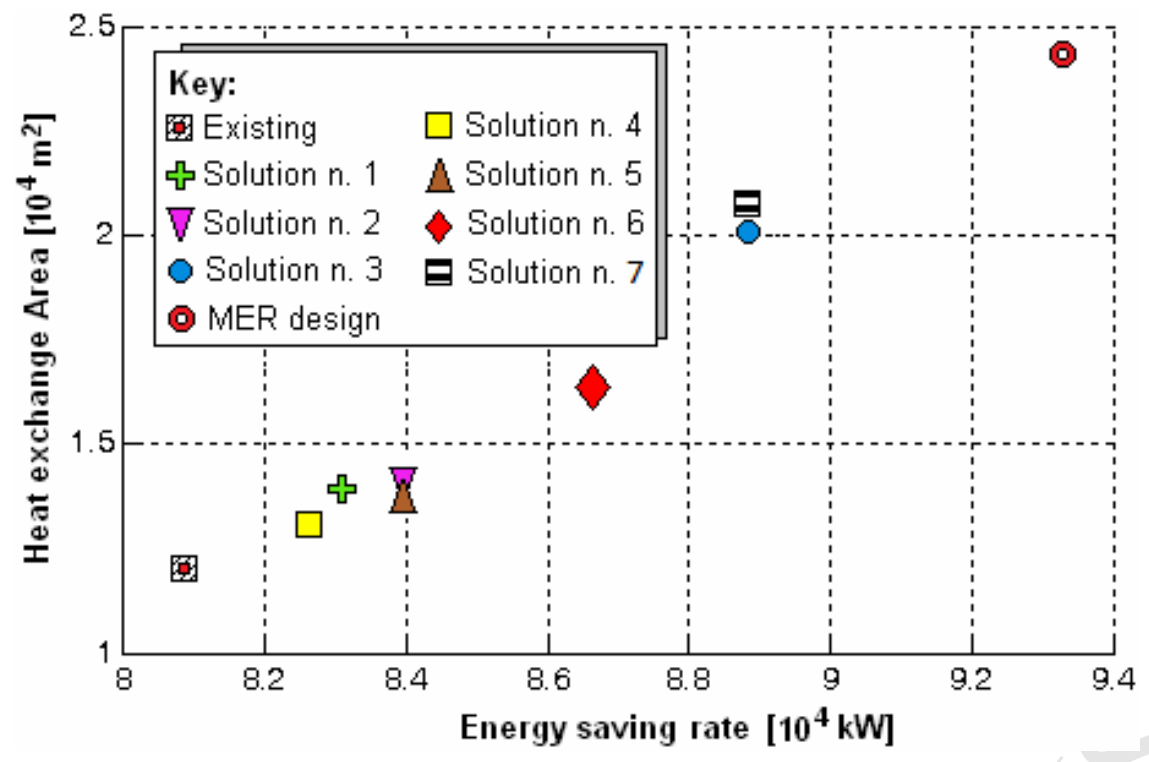

Fig. 11.

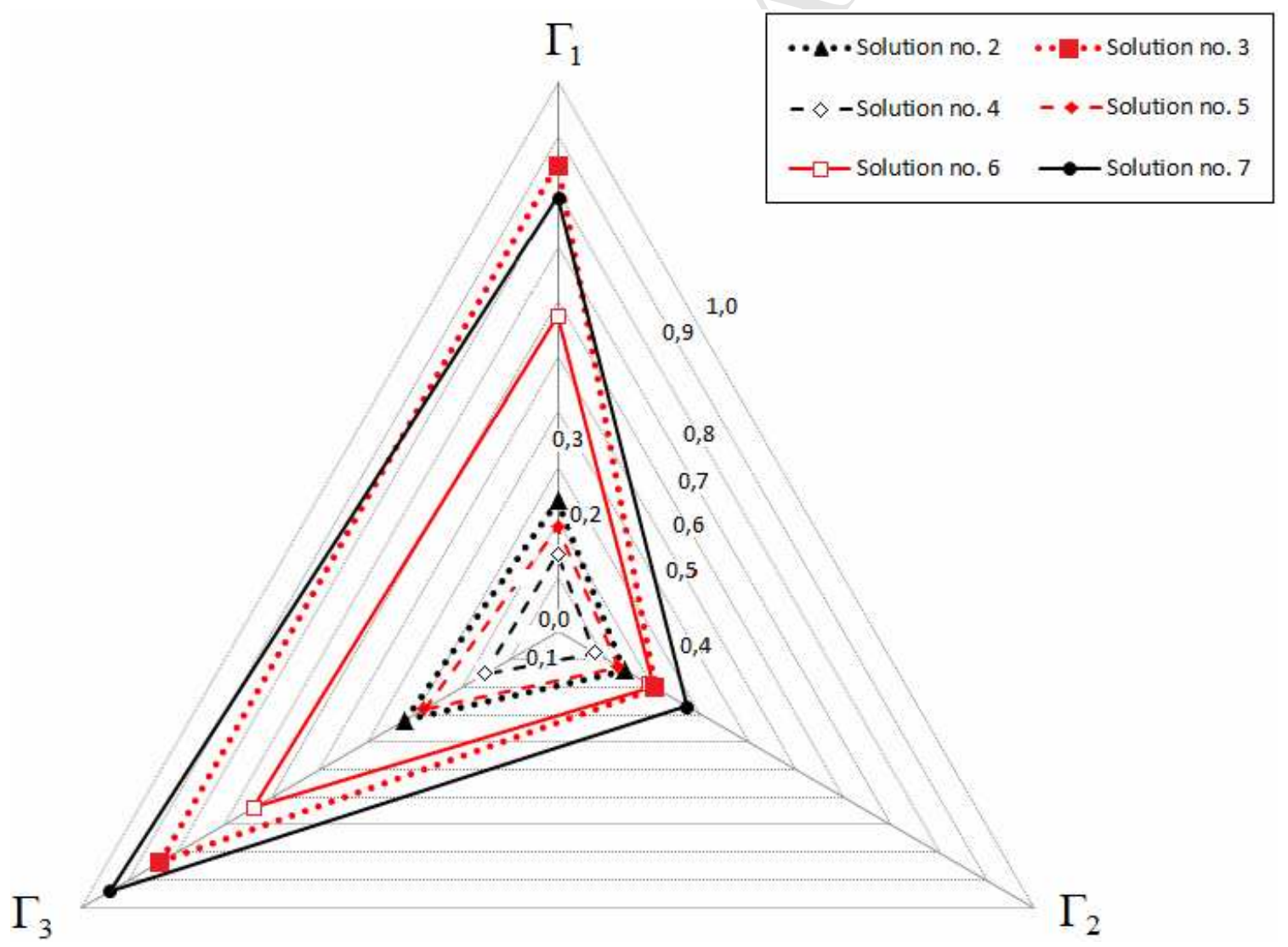

Fig. 12. 


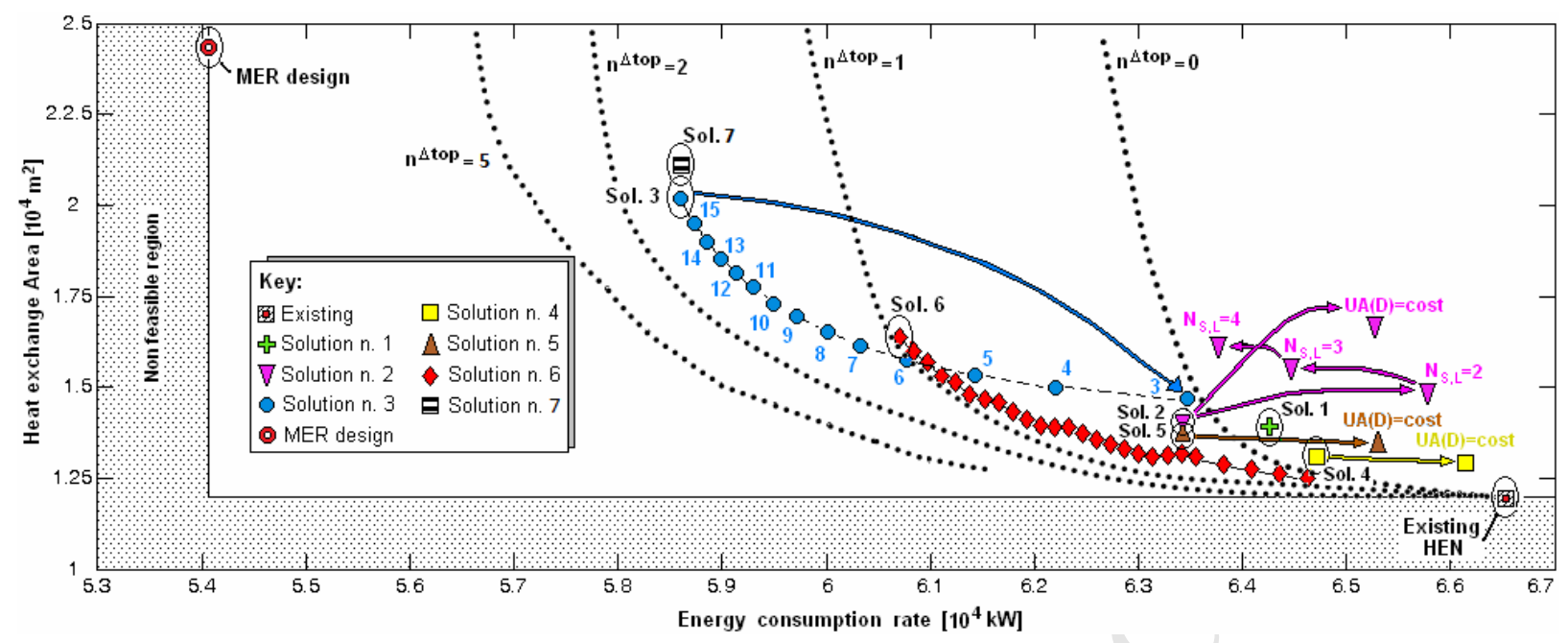

Fig. 13. 


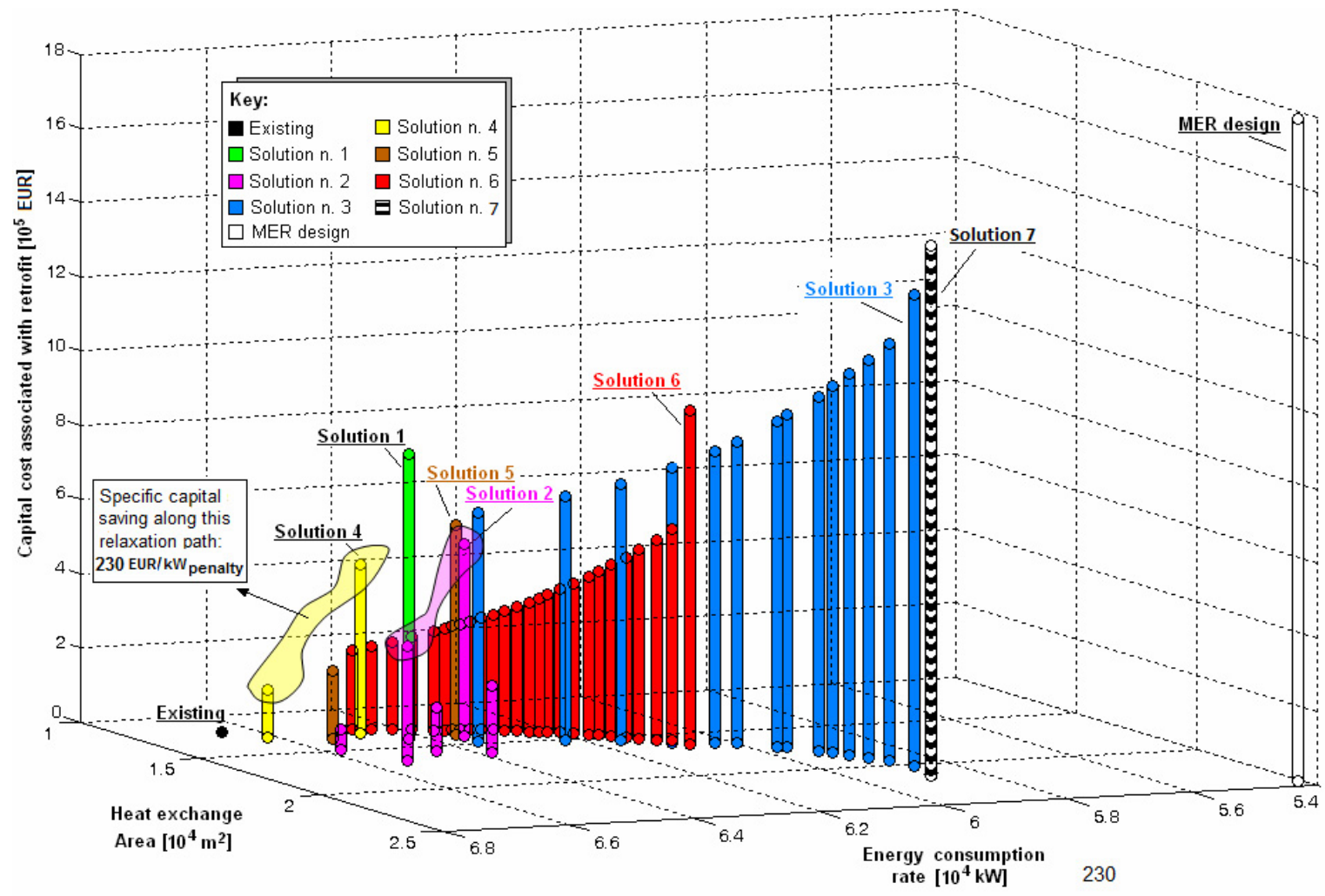

Fig. 14.a.

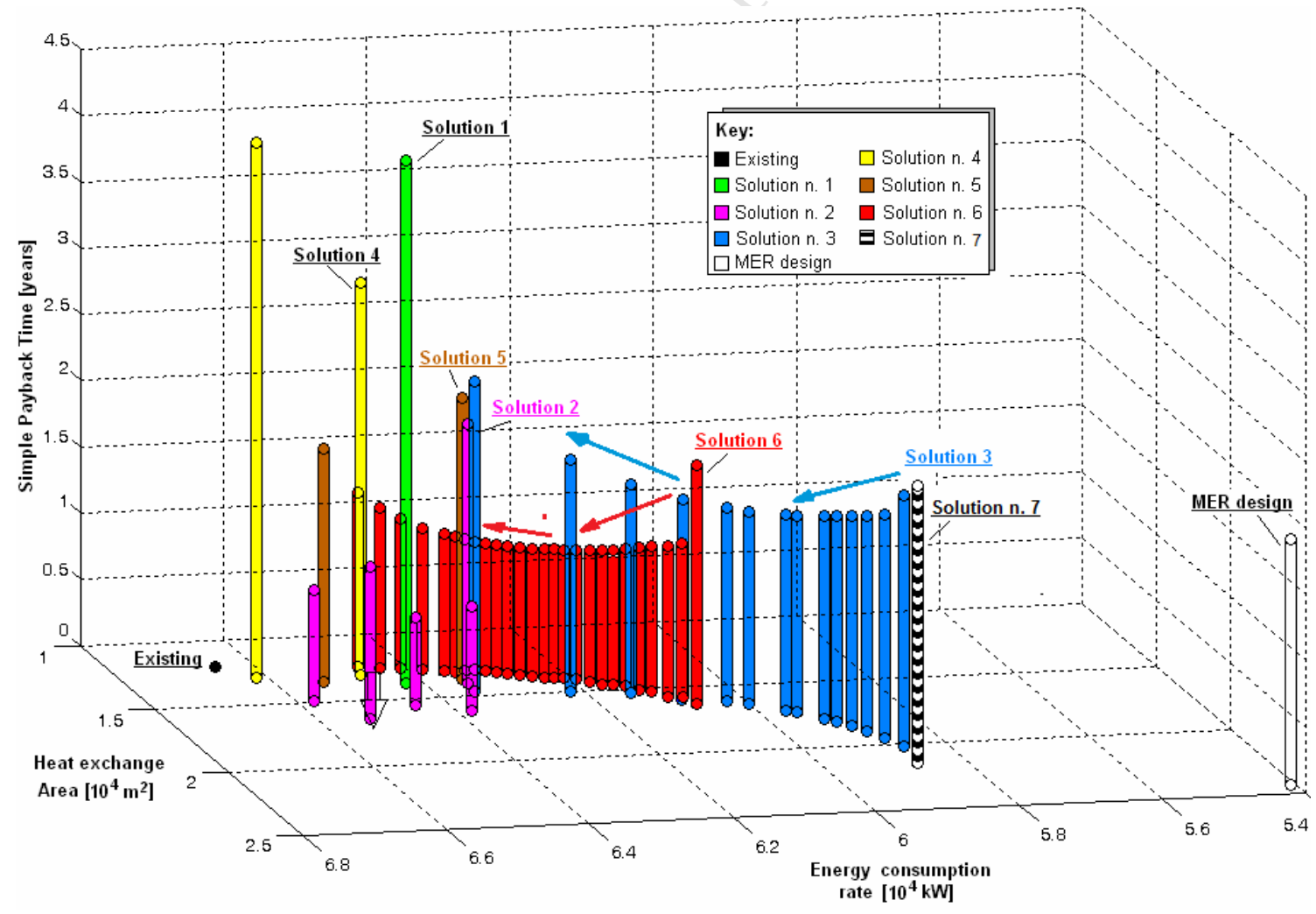

Fig. 14.b. 
Step 1:

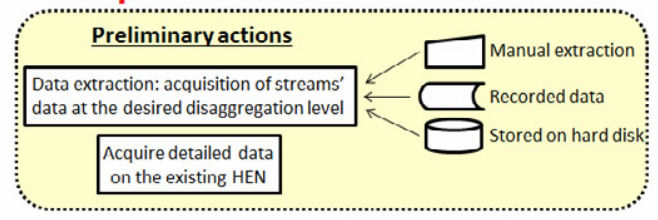

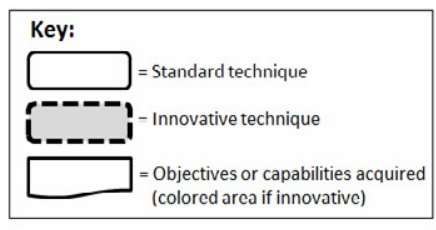

Step 2-a:

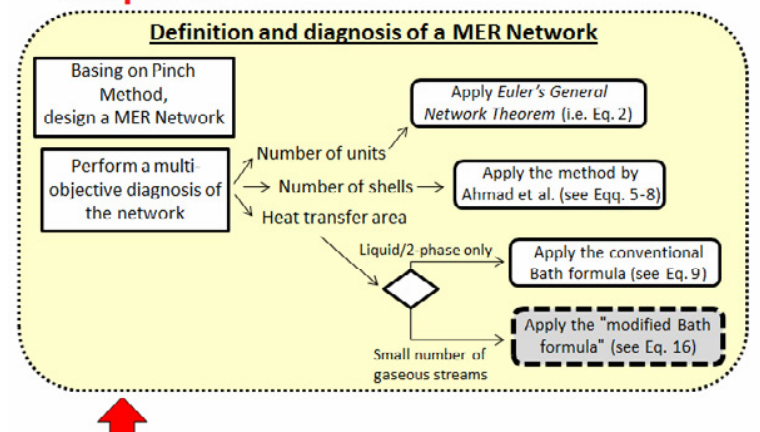

Step 2-b:

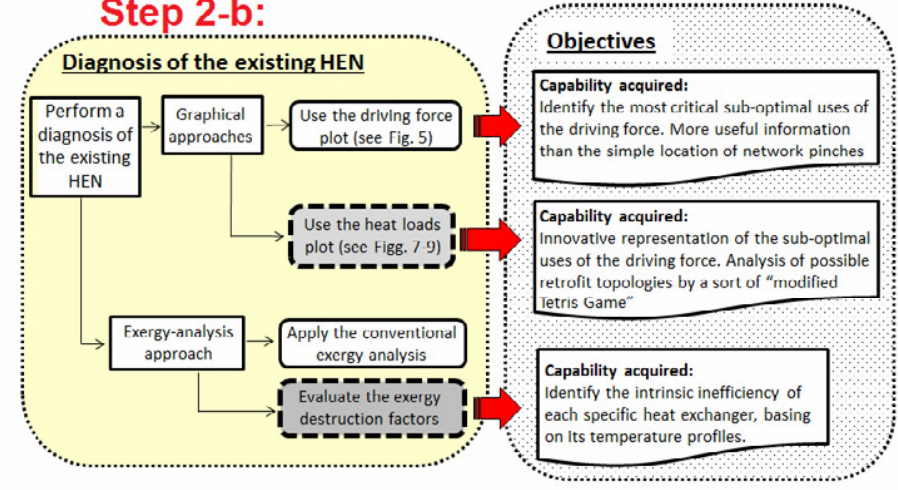

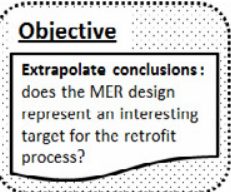

\section{Step 3:}
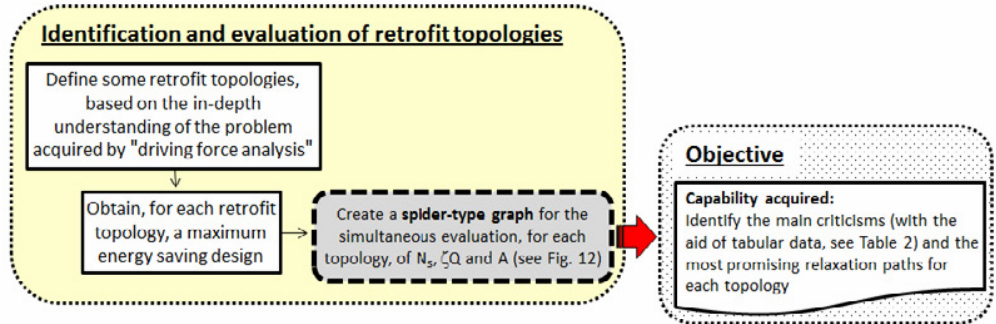

\section{Step 4:}

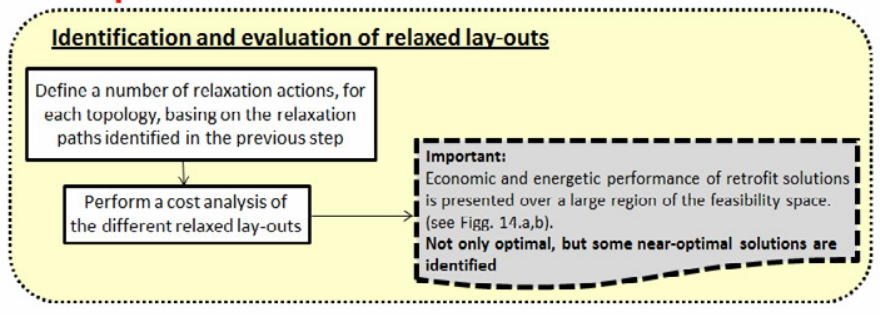

Final step:

Identify the optimal solution and, after

evaluation, proceeds with engineering it

Fig. 15 
Table 1.Data disaggregated at sub-stream level for the examined aromatics plant

\begin{tabular}{|c|c|c|c|c|c|}
\hline Stream & Sub-stream & $\begin{array}{l}\text { Supply } \\
\text { temperature }\left[{ }^{\circ} \mathrm{C}\right]\end{array}$ & $\begin{array}{l}\text { "Final"/“Target" } \\
\text { temperature }\left[{ }^{\circ} \mathrm{C}\right]\end{array}$ & $\begin{array}{c}\text { Heat load Q } \\
{[\mathrm{kW}]}\end{array}$ & $\mathrm{G} \overline{\mathrm{c}_{\mathrm{p}}}\left[\mathrm{kW} /{ }^{\circ} \mathrm{C}\right]$ \\
\hline \multirow{2}{*}{1} & $1 \mathrm{a}$ & 102 & 229 & $16,165.7$ & 127.29 \\
\hline & $1 \mathrm{~b}$ & 229 & 327 & $9,652.9$ & 98.50 \\
\hline \multirow{3}{*}{2} & $2 \mathrm{a}$ & 327 & 174 & $16,165.7$ & 105.66 \\
\hline & $2 b$ & 174 & 92 & $10,467.0$ & 127.65 \\
\hline & $2 c$ & 92 & 50 & $4,884.6$ & 116.30 \\
\hline 3 & - & 35 & 164 & $10,467.0$ & 81.14 \\
\hline \multirow{3}{*}{4} & $4 a$ & 140 & 176 & $8,373.6$ & 232.60 \\
\hline & $4 b$ & 176 & 367 & $29,307.6$ & 153.44 \\
\hline & $4 c$ & 367 & 500 & $19,073.2$ & 143.41 \\
\hline 5 & - & 495 & 307 & $29,307.6$ & 155.89 \\
\hline \multirow{4}{*}{6} & $6 a$ & 220 & 160 & $8,373.6$ & 139.56 \\
\hline & $6 b$ & 160 & 144 & $3,837.9$ & 239.87 \\
\hline & $6 \mathrm{c}$ & 144 & 125 & $4,768.3$ & 250.96 \\
\hline & $6 \mathrm{~d}$ & 125 & 59 & $13,490.8$ & 204.41 \\
\hline 7 & - & 80 & 123 & $3,837.9$ & 89.25 \\
\hline 8 & - & 59 & 169 & $7,908.4$ & 71.89 \\
\hline \multirow{2}{*}{9} & $9 a$ & 222 & 130 & $7,908.4$ & 85.96 \\
\hline & $9 b$ & 130 & 67 & $4,419.4$ & 70.15 \\
\hline 10 & - & 85 & 125 & $4,768.3$ & 119.21 \\
\hline 11 & - & 480 & 500 & $37,797.5$ & $1,889.87$ \\
\hline
\end{tabular}


Table 2. Critical items for the retrofit topologies no. 2, 3 and 4

\begin{tabular}{|c|c|c|c|}
\hline & Highest $\mathrm{N}_{\mathrm{s}}$ & Highest $\zeta Q$ & Highest $\mathrm{A}=\frac{\mathrm{Q}}{\mathrm{K} \cdot \Delta \mathrm{T}_{\mathrm{lm}}}$ \\
\hline Retrofit topology no. 2 & $\begin{array}{c}\text { Heat exchanger L: } 5 \text { shells } \\
\ldots\end{array}$ & $\begin{array}{c}\text { Heat exchanger D: } 2.51 \mathrm{MW} \\
\text { Heat exchanger A: } 1.76 \mathrm{MW} \\
\ldots\end{array}$ & $\begin{array}{c}\text { Heat exchanger A: } 1538 \mathrm{~m}^{2} \\
\text { Heat exchanger L: } 1452 \mathrm{~m}^{2} \\
\ldots\end{array}$ \\
\hline Retrofit topology no. 3 & $\begin{array}{l}\text { Heat exchanger A: } 16 \text { shells } \\
\text { Heat exchanger L: } 9 \text { shells }\end{array}$ & $\begin{array}{l}\text { Heat exchanger D: } 3.11 \mathrm{MW} \\
\text { Heat exchanger B: } 0.93 \mathrm{MW}\end{array}$ & Heat exchanger A: $7343 \mathrm{~m}^{2}$ \\
\hline Retrofit topology no. 4 & No critical heat exchangers & $\begin{array}{l}\text { Heat exchanger D: } 3.11 \mathrm{MW} \\
\text { Heat exchanger A: } 1.76 \mathrm{MW}\end{array}$ & Heat exchanger D: $1386 \mathrm{~m}^{2}$ \\
\hline
\end{tabular}

